\title{
The memory of stock return volatility: asset pricing implications
}

Article

Accepted Version

Nguyen, D. B. B., Prokopczuk, M. and Sibbertsen, P. (2020)

The memory of stock return volatility: asset pricing implications. Journal of Financial Markets, 47. 100487. ISSN 1386-4181 doi: https://doi.org/10.1016/j.finmar.2019.01.002 Available at https://centaur.reading.ac.uk/82171/

It is advisable to refer to the publisher's version if you intend to cite from the work. See Guidance on citing.

To link to this article DOI: http://dx.doi.org/10.1016/j.finmar.2019.01.002

Publisher: Elsevier

All outputs in CentAUR are protected by Intellectual Property Rights law, including copyright law. Copyright and IPR is retained by the creators or other copyright holders. Terms and conditions for use of this material are defined in the End User Agreement.

\section{www.reading.ac.uk/centaur}

\section{CentAUR}

Central Archive at the University of Reading

Reading's research outputs online 


\title{
The memory of stock return volatility:
}

\section{Asset pricing implications*}

\author{
Duc Binh Benno Nguyen ${ }^{\dagger} \quad$ Marcel Prokopczuk ${ }^{\dagger, \ddagger} \quad$ Philipp Sibbertsen $^{\dagger}$
}

\begin{abstract}
We examine long memory volatility in the cross-section of stock returns. We show that long memory volatility is widespread in the United States and that the degree of memory can be related to firm characteristics, such as market capitalization, book-to-market ratio, prior performance, and price jumps. Long memory volatility is negatively priced in the cross-section. Buying stocks with shorter memory and selling stocks with longer memory in volatility generates significant excess returns of $1.71 \%$ per annum. Consistent with theory, we find that the volatility of stocks with longer memory is more predictable than stocks with shorter memory. This makes the latter more uncertain, which is compensated for with higher average returns.
\end{abstract}

JEL classification: C22, G12

Keywords: Asset pricing; Long memory; Persistence; Volatility

*We thank an anonymous referee, Fabian Hollstein, Frederik Middelhoff, Matthias Pelster as well as participants at the meeting of the German Finance Association (2017), the Auckland Finance Meeting (2017), the Annual Meeting of the Financial Management Association (2018), and several seminars for valuable comments. Contact: nguyen@fmt.uni-hannover.de (D.B.B Nguyen), prokopczuk@fmt.unihannover.de (M. Prokopczuk), and sibbertsen@statistik.uni-hannover.de (P. Sibbertsen).

${ }^{\dagger}$ School of Economics and Management, Leibniz University Hannover, Koenigsworther Platz 1, 30167 Hannover, Germany.

${ }^{\ddagger}$ ICMA Centre, Henley Business School, University of Reading, Reading, RG6 6BA, U.K. 


\section{Introduction}

To the best of our knowledge, we are the first to analyze the asset pricing implications of long memory volatility in the cross-section of U.S. stocks. We show that long memory is prevalent in the volatility of individual stock returns. Long memory can be related to the size, past performance, and the jump intensity of a firm. Moreover, we provide time-series and cross-sectional evidence for a negative price of long memory volatility in the cross-section of stock returns.

We study the implications of long memory by building on three strands of literature. First, we extend the research on documenting long memory, which, has only focused on indices or some large firms by investigating the complete cross-section of U.S. stocks. Second, we analyze the time variation of long memory in volatility. Third, long memory has only been analyzed in the time series dimension, not in the cross-sectional one. We discuss and investigate possible microeconomic fundamentals, which may explain long memory, and examine whether memory is a priced factor.

We find that $95 \%$ of stocks possess long memory in volatility, with an average memory parameter of 0.22 . At the firm level, higher volatility memory estimates are related to larger size, worse prior performance, and fewer price jumps. Following the investment strategy of holding stocks with shorter memory volatility and shorting stocks with longer memory volatility generates excess returns of $1.71 \%$ per annum. This result is supported by cross-sectional regression tests. We find a significant risk premium for the memory parameter where stocks with anti-persistent volatility can earn up to $4.7 \%$ per annum more than stocks with long memory volatility. We show that the volatility of stocks with higher memory parameters is more predictable than stocks with low memory parameters. This indicates that the lower uncertainty of stocks with longer memory (i.e., more 
persistent volatility) results in a negative premium. ${ }^{1}$ Our results are robust to controling for idiosyncratic volatility, size, and other characteristics, as well as to various additional tests. At the same time, we verify our memory estimates by showing that forecasting volatility for stocks with longer memory works better than for stocks with shorter memory. We also relate our results to theoretical models, which show how long memory is generated through heterogeneity in the market.

Long memory processes (also referred to as long-range dependent processes) are present in numerous sciences and fields such as physics, geophysics, hydrology, climatology, biology and, most importantly for the subject of this project, economics and finance. Long memory processes can be described as long-range dependent time series with a hyperbolic decaying autocorrelation function, as opposed to the exponential function of short memory processes such as autoregressive processes. The introduction of long memory processes created a huge wave of new time-series models and methodologies to analyze, estimate, and predict them, since the old methods used for short memory time series were no longer appropriate. The first study to mention is perhaps ?, who examines the Nile River in order to understand the persistence of stream flow data. There are also several papers dealing with long memory in economics and finance. ? provides a detailed survey and review for this purpose. The most common models are the autoregressive fractionally integrated moving average (ARFIMA) model by ?, ? and ? and the fractionally integrated generalized autoregressive conditional heteroskedasticity (FIGARCH) model introduced by ?. These are extensions of the short memory ARMA and GARCH models, respectively. Long memory properties have been analyzed comprehensively in returns and volatilities and our paper draws from several strands of literature.

\footnotetext{
${ }^{1}$ In recent studies, ? and ? show that volatility-of-volatility is priced in the cross-section of stock returns. Although one might think that volatility-of-volatility is related to the degree of long memory in volatility, we empirically show that (i) it is not, and (ii) it is priced separately.
} 
The first strand focuses on the estimation and detection of long memory in the volatility of stock returns. Shortly after the introduction of the FIGARCH model, ? and ? show that the conditional variance and absolute returns of the S\&P 500 Index, respectively, possess long memory. ? also find long memory in the variance of equally-weighted and value-weighted Center for Research in Security Prices (CRSP) stock market index returns. ? investigate the long memory properties of the U.S. stock market index and 30 individual stock returns in the U.S., while ? and ? consider the long memory property of various international stock indices, including Germany, Japan, Korea, New Zealand, Malaysia, Singapore, Taiwan, and the U.S.

Another strand of the literature covers breaks in the long memory parameter, and hence allows memory to vary over time. ? consider long memory dynamics and introduce a methodology to test for a break from stationary long memory to non-stationary long memory. Their test is improved by ?, since the results may be distorted when the datagenerating process exhibits long memory. They apply the test to U.S. inflation data and find a break in the early 1980s. ? test for the persistence of European Monetary Union government bond yields for France, Italy, and Spain, using the same methodology, and find breaks between 2006 and 2008 .

Our paper is mostly related to the asset pricing literature. The research and discovery of anomalies and effects that can explain the cross-section of expected returns is constantly growing since the introduction of the capital asset pricing model (CAPM) (????). In addition to the market portfolio, ? show that a three-factor model including size and book-to-market ratio is better able to capture the cross-sectional variation in average stock returns. ? adds a momentum factor to the three-factor model, and more recently, ? extend their three-factor model by adding profitability and investment factors. The 
list of potential explanatory variables for the cross-sectional variation of stock returns is ongoing. For example, to name only two, ? finds a positive relationship between the illiquidity of stocks and future excess returns while ? show that idiosyncratic volatility is negatively priced in the cross-section. ? propose the q-factor model including market, size, investment, and profitability factors, and show that the performance of their model is at least as good as the models proposed by ? and ?.

The rest of the paper is organized as follows. In Section 2, we describe our data set and estimation procedure for long memory. In Section 3, we examine the cross-section of U.S. stocks. In Section 4, we relate long memory to predictability. In Section 5, we discuss the origin of long memory. Robustness tests are presented in Section 6. Concluding remarks are given in Section 7.

\section{Data and methodology}

\section{$2.1 \quad$ Data}

The data used for our analyses come from various sources. For our cross-sectional analysis of U.S. stock returns, we obtain equity prices, returns, market capitalization, and volume data from CRSP for the period from January 1926 to December 2015. In our main analysis, we investigate four different firm characteristics that have been shown in the literature to be priced in the cross-section of stock returns. They include size, value, momentum effects, and the liquidity factor. The construction of the variables, which we refer to as size, book-to-market, momentum, and illiquidity, follows the convention of the literature (see ????, among others) and are based on market capitalizations, returns and 
trading volumes from CRSP and balance sheet information from Compustat. ${ }^{2}$

High-frequency price data are obtained from Thomson Reuters Tick History. When employing high-frequency data, the analysis is restricted to the period from January 1996 to December 2015 and on the S\&P 500 constituents only. ${ }^{3}$

\subsection{Semiparametric estimation of long memory in volatility}

Our estimation of the long memory parameter relies on two of the most popular estimators: the GPH estimator and the Local Whittle estimator.

The first is based on the log-periodogram and was developed by ?. The GPH estimator employs a linear regression using the first $m$ periodogram ordinates and exploits the shape of the spectral density around the origin. The spectral density of a stationary process $X_{t}$ is estimated empirically by the periodogram:

$$
I_{X}\left(\lambda_{j}\right)=\frac{1}{2 \pi N}\left|\sum_{t=1}^{N} X_{t} e^{-i t \lambda}\right|^{2}, \quad t=1, \ldots, N
$$

where the periodogram is not affected by centering of the time series for Fourier frequencies $\lambda_{j}=2 \pi j / N(j=1, \ldots,[(N-1) / 2])$. The estimator is given by the negative slope estimate $\beta_{1}$ in the regression:

$$
\log \left(I\left(\lambda_{j}\right)\right)=\beta_{0}+\beta_{1} \log \left[4 \sin ^{2}\left(\lambda_{j} / 2\right)\right]+\epsilon_{j}, \quad j=1, \ldots, m
$$

\footnotetext{
${ }^{2}$ Even though the size factor is constructed by calculating the logarithm of the market capitalization, we refer to this factor as size rather than $\log ($ size).

${ }^{3}$ This choice is due to the restricted availability of high-frequency data for the complete cross-section, which is crucial for our long memory estimates.
} 
Under mild conditions $\left(m \rightarrow \infty, N \rightarrow \infty, \frac{m}{N} \rightarrow 0\right)$, ? derives the asymptotic distribution:

$$
\sqrt{m}(\hat{d}-d) \underset{d}{\longrightarrow} N\left(0, \frac{\pi^{2}}{24}\right)
$$

which provides the asymptotic standard errors for the long memory parameter. The estimator is narrowband since the bandwidth parameter $m$ leads to a bias-variance tradeoff. While a high $m$ far from the origin leads to bias, a low $m$ too close to the origin leads to a rise in the variance.

The second estimator is the Local Whittle estimator, which is obtained by minimizing the following objective function:

$$
\hat{d}_{L W}=\underset{d \in \theta}{\arg \min }\left[\log \left(\frac{1}{m} \sum_{j=1}^{m} \frac{I\left(\lambda_{j}\right)}{\lambda_{j}^{2 d}}\right)-\frac{2 d}{m} \sum_{j=1}^{m} \log \lambda_{j}\right], \quad \theta \subseteq(-0.5,0.5),
$$

where $m$ is restricted to $m<\frac{N}{2}$. The Local Whittle estimator is an extension of the one originally proposed by ?, which relies on an approximate maximum likelihood approach. Under mild assumptions similar to those for the GPH estimator, ? derives the asymptotic distribution:

$$
\sqrt{m}\left(\hat{d}_{L W}-d_{0}\right) \underset{d}{\longrightarrow} N\left(0, \frac{1}{4}\right)
$$

For our main analysis, we focus on the GPH estimator and the bandwidth $m=N^{0.5}$ following the literature (????). ${ }^{4}$ The results with alternative bandwidth choices and the Local Whittle estimator are reported in the robustness section, Section 6 .

We refer to $d$ as the memory parameter and differentiate between three cases: A time

\footnotetext{
${ }^{4}$ Typically, empirical researchers rely on this bandwidth choice since it is robust against short-range dependencies in the data. In terms of mean squared error (MSE) improvement, ? argue that the bandwidth $m=O\left(N^{0.8}\right)$ is the optimal choice.
} 
series has short memory if $d=0$. A time series has negative memory or is anti-persistent if $d<0$. A time series has long memory if $0<d<1$ where it is non-stationary if $0.5<d<1$

\section{Long memory volatility in the cross-section of stock}

\section{returns}

\subsection{Descriptive statistics}

We apply the GPH estimator to the time series of squared returns for the cross-section of U.S. stocks. Since we are interested in the relationship between memory, firm characteristics, and expected returns, we allow for a time-varying memory parameter. More specifically, we estimate the memory parameter at a monthly frequency using a rolling window, which includes the most recent five years of daily return observations. ${ }^{5}$ Table 1 provides summary statistics for the memory parameter estimates. In our sample period, we have on average 2,480 memory parameter estimates at each point of time. The average estimate is 0.22 with a standard deviation of 0.12 . The mean t-statistic of 23.34 suggests that the memory parameter is statistically significant on average. Also, we find that most of the stocks exhibit long memory in volatility; $95 \%$ of the stocks show a memory parameter with $0.0<d<0.5$, while $3 \%$ of the stocks are anti-persistent and only $2 \%$ show non-stationary long memory.

Our results are consistent with the literature and extend the evidence of long memory in stock return volatility to a broader cross-section. ?, for example, find that components of the Dow Jones Index show strong evidence of long memory in squared returns for the

\footnotetext{
${ }^{5}$ We require at least non-missing return observations on $50 \%$ of the days over the examined period for a stock to be included in our analysis.
} 
period from July 1962 to December 1994. ? find for the equally-weighted CRSP portfolio for the period from 1962 to 1989 a memory parameter of $d=0.22$, which coincides with both the mean and the median from our analysis of the complete cross-section of U.S. stocks.

\subsection{Explaining long memory with firm characteristics}

In this subsection, we relate the memory parameter of a stock's volatility to firm characteristics. We include size, book-to-market, momentum, and illiquidity. These variables have been shown to be priced in the cross-section of stock returns (????). We also include two jump measures since recent studies have shown that jumps are an important factor in the cross-section of stock returns. ? analyze the predictability of cross-sectional stock returns and find that once controling for jumps, firm characteristics such as size and liquidity are no longer predictive. ? and ? show that the sensitivity of stocks to market tail and jump risk helps to explain the cross-sectional variation in expected returns. We apply the common jump test proposed by ? (BNS). ${ }^{6}$ The test relies on the bipower variation, which decomposes the quadratic variation into its parts due to continuous movements and a jump part. The jump test statistic is given by:

$$
\begin{aligned}
B N S_{t} & =\frac{(\pi / 2) B_{t}-S_{t}}{\sqrt{\left(\left(\pi^{2} / 4\right)+\pi-5\right)(\pi / 2)^{2} Q_{t}}} \\
Q_{t} & =\frac{1}{K_{t}-3} \sum_{k=4}^{K_{t}}\left|r_{t, k}\right|\left|r_{t, k-1}\right|\left|r_{t, k-2}\right|\left|r_{t, k-3}\right| \\
S_{t} & =\frac{1}{K_{t}} \sum_{k=1}^{K_{t}} r_{t, k}^{2} \\
B_{t} & =\frac{1}{K_{t}-1} \sum_{k=2}^{K_{t}}\left|r_{t, k}\right|\left|r_{t, k-1}\right|,
\end{aligned}
$$

${ }^{6} ?$ show with the help of simulations using different jump size and frequency, that this test is preferable to those proposed by ?, ?, and ?. 
where $K_{t}$ is the number of observations over the examined period, $r_{t, k}$ is the $k$ th daily observation over the examined period $t$, and $B N S_{t}$ is normally distributed under the null. First, we compute the BNS jump statistic for each month and stock using daily return data within each calender month following ?. The first measure of jump intensity is given by the jump test statistic (BNS). Our second measure is a dummy variable indicating whether the current month includes a significant jump at the $5 \%$ level, which we denote as BNS-I.

Each month for the period from January 1950 to December 2015, we sort all stocks into quintile portfolios where stocks with the lowest memory parameter are in the first quintile and stocks with the highest memory parameter are in the fifth quintile. We then track the average firm characteristics of these quintile portfolios. ${ }^{7}$

Table 2 shows the results. We report the average memory and firm characteristics for each quintile and for the long memory minus short memory (LMS) portfolio. For the latter, we also present t-statistics in parentheses in the last column. Average portfolio size, momentum, and jump measures demonstrate a monotonic pattern that is increasing/decreasing in the memory parameter. Stocks with higher market capitalization, worse past performance, and fewer jumps (higher jump statistics and fewer significant jumps) exhibit longer memory in volatility. These differences are highly statistically significant with absolute t-statistics above 12. There is no monotonic pattern for Book-to-Market and Illiquidity but the hedge portfolio shows positive values for both and the t-statistic is statistically significant for Illiquidity.

We complement the above analysis with cross-sectional regressions. At each point of time, we regress the memory parameter of each firm on the predictor variables in the

\footnotetext{
${ }^{7}$ We start our analysis in 1950 because book-to-market data are available only from 1950 in Compustat.
} 
following regression:

$$
d_{i, t}=\alpha_{t}+\beta_{t} X_{i, t}+\epsilon_{i, t}
$$

where $d_{i, t}$ is the memory estimate of stock $i$ at time $t, X_{i, t}$ is the vector containing the firm characteristics of stock $i$ at time $t$, and $\epsilon_{i}$ is the error term. ${ }^{8}$ The slope coefficients are expected to have signs as the LMS portfolio spreads. The coefficients are reported in Table 3 for three regressions. The first row shows the results when excluding the jump measures, the second when including the BNS jump statistic, and the third when including the jump dummy variable. In accordance with our portfolio sorts, stocks with large Size, worse prior performance, and fewer jumps (higher jump statistics and fewer significant jumps) exhibit higher memory parameters. The coefficients are all statistically significant at the $1 \%$ level. We additionally find that value stocks possess higher memory parameters, while illiquidity does not provide explanatory power for the degree of memory in volatility. Intuitively, stocks that tend to exhibit jumps more frequently, are less persistent and predictable and should possess lower memory parameters. We show the close connection of long memory and predictability in Section 4 and provide some intuition for how memory is generated for small (large) and loser (winner) stocks in Section 5.

\subsection{Long memory volatility and expected stock returns: portfolio}

\section{sorts}

In previous sections we relate the memory of volatility to firm-specific variables, trying to explain the degree of long memory. In the next step, we investigate whether investors

\footnotetext{
${ }^{8}$ We experiment with multiple alternative estimation methods for long memory in order to make sure that the results are robust with respect to the estimation approach. The methods and results are reported in Subsection 6.4 and are qualitatively similar.
} 
demand a compensation for holding assets with higher exposure to this factor by looking at the relationship between the degree of memory in volatility and realized future excess stock returns. Assuming that the degree of memory in volatility is related to the predictability of a stock return's volatility, a highly predictable stock should be less uncertain than an unpredictable stock. We hence expect a negative price for long memory in order to compensate investors for the additional volatility risk of short memory stocks. ${ }^{9}$

As in Subsection 3.2, for each month, we sort all stocks into quintile portfolios where stocks with the lowest memory parameter are in the first quintile and stocks with the highest memory parameter are in the fifth quintile. Excess returns of the equally-weighted portfolios are tracked over the subsequent month. ${ }^{10}$ The analysis is out-of-sample in the sense that there is no overlap between the data used for the memory estimation and the data used to compute the excess returns of the portfolios. The LMS portfolio returns are then regressed on risk factors to test whether these returns merely reflect passive exposure to standard factors. We include the market portfolio of the CAPM, which controls for systematic risk and the ? three-factor model (FF3), which additionally includes the size and value effects. Further, we employ the state-of-the art ? five-factor model (FF5), and the $? q$-factor model (HXZ). ${ }^{11}$ We investigate three different sample periods, which start in 1926, 1963, and 1967, respectively. All periods end in December 2015. ${ }^{12}$

The results are presented in Table 4. We report the mean return of the quintile

\footnotetext{
${ }^{9}$ In Section 4, we use a validity check to confirm the intuitive relationship between memory and the predictability of a stock's volatility.

${ }^{10}$ Since our memory estimates $d_{i, t}$ rely on rolling window estimates, one might argue that there is barely temporal variation in our estimates. If this is true, this should work against our empirical analysis and we should not find any significant relationship between memory and expected returns, but we do. In the robustness section, Section 6, we repeat the analysis, relying on monthly memory parameters estimated from high-frequency data in that month. The results are qualitatively similar.

${ }^{11}$ The factors for the first three models are available from the Kenneth French's data library, website: mba.tuck.dartmouth.edu/pages/faculty/ken.french. The factors of the ? model were kindly provided by the authors.

${ }^{12}$ The choice of different sample periods is motivated by the availability of the factor models. The ? factors are available starting in 1963 while the ? factors are available starting in 1967.
} 
portfolios and the LMS portfolio (Q5-Q1) and the alphas of the three different models. We find that the annualized mean return generally adheres to a decreasing pattern from $13.57 \%$ in the first quintile to $11.86 \%$ in the fifth quintile. All quintile portfolio returns are statistically significant, just like the difference of $-1.71 \%$ between the long memory quintile and the short memory quintile (LMS). Controling for risk factors leads to alphas of $-2.23 \%,-2.47 \%,-2.84 \%$, and $-2.52 \%$ for the CAPM, ? three-factor model, ? fivefactor, and ? $q$-factor model, respectively. The risk-adjusted returns are all statistically significant. ${ }^{13}$

Consequently, controling for standard risk factors does not affect our main result that the long memory volatility excess return trade-off is priced with a negative sign. ${ }^{14}$

\subsection{Long memory volatility and expected stock returns: regres-}

\section{sion tests}

The portfolio sorts present strong evidence that the degree of long memory in volatility is (negatively) related to future excess returns. We estimate ? regressions in which we simultaneously control for different variables and test whether the degree of memory of a stock's volatility contains information about future excess returns beyond that of various other firm characteristics. This exercise, which relies on individual stock returns rather than stock portfolios, presents an alternative method to estimate the cross-sectional risk

\footnotetext{
${ }^{13}$ We focus on equally-weighted portfolios. We have redone the analysis with value-weighted portfolios, which leads to a spread return of $-2.27 \%$ and a FF5 alpha of $-2.19 \%$. Both are statistically significant at the $10 \%$ level.

${ }^{14}$ As shown in Subsection 3.2, the memory parameter can be explained by firm characteristics such as size, jumps, and momentum. Nonetheless, controling for the risk factors delivers statistically significant alphas. As an additional robustness check, we investigate whether the isolated effect of long memory, which is orthogonal to firm size and other firm characteristics, is priced in the cross-section as well. Residual long memory is obtained by regressing the memory parameter on the firm characteristics at each point of time following ?, ?, and ?. We find a CAPM (FF5) alpha of $-1.2 \%(-1.5 \%)$, which is statistically significant at the $10 \%$ level or lower. Results are reported in Table 10 in the Online Appendix.
} 
premium associated with long memory volatility. We rely on individual stocks rather than portfolio returns since the formation of portfolios in cross-sectional regressions is shown to influence the results and lead to higher standard errors of the risk premium estimates (???). for each month, we regress excess stock returns over the following month on the stock characteristics of the current month:

$$
r_{i, t+1}-r_{f, t+1}=\alpha_{t}+\gamma_{t}^{M} d_{i, t}+\gamma_{t}^{C} X_{i, t}+\epsilon_{i, t+1}
$$

where $r_{i, t}$ is the return of stock $i$ and $r_{f, t}$ is the risk-free rate at time $t . X_{i, t}$ is a vector containing the firm characteristics size, book-to-market, momentum, illiquidity and jumps. ${ }^{15}$ $\gamma_{t}^{M}$ and $\gamma_{t}^{C}$ are the risk premia associated with the memory parameter and the remaining firm characteristics, respectively, and $\epsilon_{i, t}$ is the error term. In a second step, we perform tests on the time-series averages of the estimated monthly intercept and slope coefficients to test for the significance of the risk premia $\hat{\gamma}_{t}^{M}$ and $\hat{\gamma}_{t}^{C}$ over the sample period.

Table 5 reports the results of the ? regressions presenting the time-series averages of the coefficients, $\hat{\alpha}_{t}, \hat{\gamma}_{t}^{M}$, and $\hat{\gamma}_{t}^{C}$. In Model 1, we regress the excess return of stocks over the following month on the memory parameter only. The market price of long memory is -0.0039 , which is statistically significant at the $5 \%$ level. Consequently, a stock with anti-persistent volatility can earn average annualized returns of up to $4.7 \%$ higher than a stock with long memory volatility. ${ }^{16}$ Models 2 to 6 additionally include one of the

\footnotetext{
${ }^{15}$ We use the same firm characteristics as in our portfolio sorts in Subsection 3.3.2. We include further control variables such as the market beta, idiosyncratic volatility, and more in the robustness section, Section 6. Moreover, we acknowledge the potential errors-in-variables (EIV) problem since our long memory parameters are pre-estimated before being included in the cross-sectional regressions. While our portfolio sorts, which are less strongly affected by EIV support our findings, we directly control for EIV by using the instrumental variable approach of ?. Long memory parameters are regressed on lagged (60 lags in accordance with the estimation window) parameters for which the measurement errors should be uncorrelated. We then include the fitted values from the regressions in the cross-sectional regressions instead of the long memory parameter itself. The results are qualitatively similar and we find a cross-sectional price of -0.0054 for long memory, which is statistically significant as well.

${ }^{16}$ The lowest possible memory parameter for an anti-persistent stock is given by the lower bound
} 
firm characteristics in the cross-sectional regression. The magnitude and significance of the memory risk premium is slightly reduced when adding Size but barely changes when adding book-to-market, momentum, illiquidity or jumps. Nonetheless, the coefficient $\hat{\gamma}^{M}$ remains statistically significant for all models. The negative (positive) risk premium for size (book-to-market, momentum and illiquidity) is consistent with the literature (???). The results are qualitatively similar for the kitchen sink regression (Model 7) where the coefficient of the memory parameter remains statistically significant. ${ }^{17}$

\section{Long memory volatility and predictability}

A possible explanation for the negative relationship between long memory volatility and expected stock returns is the uncertainty around a stock's volatility. As discussed earlier, long memory represents the hyperbolic decay of the autocorrelation function, which on the other hand allows for (high and long-run) volatility predictability. One can argue that in times of financial distress large negative shocks are more persistent for stocks with long memory, which makes these stocks less favorable than short memory stocks. But even though negative shocks are more persistent, the volatility predictability is still higher for long memory stocks, which makes them less uncertain regarding their level of risk.

In Subsections 3.3 and 3.4, we provide evidence that stocks with long memory volatil-

of the interval $(-0.5 ; 0)$ while the highest possible stationary memory parameter is given by the upper bound of the interval $(0 ; 0.5)$. The highest possible annualized spread returns can thus be approximated by $1 *(-0.0039) * 12=-0.0468$.

${ }^{17}$ In our main analysis, we focus on the asset pricing implications of the long memory volatility independently from the level of volatility. One might wonder whether the results depend on the level of volatility. In the robustness section, Section 6, we control for the level of volatility (along with possible controls). We find qualitatively similar results, which emphasizes that investors prefer long memory stocks due to the higher predictability of volatility conditional on the same level of volatility. For our main findings, on the other hand, long or short memory stocks could have either high or low level of volatility 
ity earn on average lower returns than stocks with short memory using both portfolio sorts and cross-sectional regressions. In this section, we supply empirical evidence that long memory is associated with predictability and hence confirm our channel of negative expected returns through volatility uncertainty. Further, this exercise is a validity check of our long memory estimates. If our memory estimates are not biased by data quality or spurious long memory, a higher memory parameter should be directly linked to higher forecasting performance. ${ }^{18}$

For each stock, we conduct monthly predictability regressions of realized volatility both in-sample and out-of-sample. The time series of monthly realized volatility is obtained by summing the squared daily returns for each month (?). Following the spirit of ?, we use (heterogenous) autoregressive models of realized volatility (HAR-RV). ${ }^{19}$ The regressions include lagged observations of the realized volatility and we allow for five different specifications by including the volatility from the previous month $(\operatorname{HAR}(1))$, six

\footnotetext{
${ }^{18}$ We acknowledge the issue of spurious long memory where higher memory parameters can be caused by structural breaks. Even though we work with rolling window estimates, which should be only marginally affected by breaks, we control for this in various different ways. First, both our portfolio sorts and cross-sectional regressions include the BNS jump statistic and the alpha or long memory risk premium remain statistically significant. Hence, our results are not driven by the BNS variable. Second, the validity check in this section relates the memory parameter to predictability. If our parameters are biased by structural breaks or jumps, we should not find any clear relationship, however we do. Third, we repeat our portfolio sorts but rely on returns purged from jumps following ?. Buying stocks with long memory volatility and selling stocks with short memory volatility, where long memory is estimated from raw returns, leads to a statistically significant spread (risk-adjusted) return of $-1.73 \%(-2.89 \%)$, which is statistically significant as well and of similar magnitudes to those in our main analysis. Forth, we consider a modified semi-parametric local Whittle estimator proposed by ?. This estimator is the most recent long memory estimator, which is robust to low frequency contaminations and robust to potential structural breaks. When sorting by the ? estimator using the parameters they propose we find a statistically significant spread (risk-adjusted) return of $-1.50 \%(-1.45 \%)$. Lastly, we apply the ? test, which tests for spurious long memory (alternative hypothesis). Relying on the suggested parameters of the author, we test for spurious long memory for each stock and each month using the rolling windows as for our long memory estimation. We filter stocks for which the null of true long memory is rejected and repeat the sorts. We find an average (risk-adjusted) return of $-0.83 \%(-1.06 \%)$, which is statistically significant as well. In summary, the negative price associated with long memory is not due to spurious long memory.

${ }^{19}$ We also experimented with simple autoregressive (AR) models including the lags $1,6,12,24$, and 60 , leading to qualitatively similar results.
} 
months $(\operatorname{HAR}(2))$, one year $(\operatorname{HAR}(3))$, two years $(\operatorname{HAR}(4))$, and 5 years $(\operatorname{HAR}(5)):{ }^{20}$

$$
\begin{aligned}
& H A R(1): R V_{t+1}^{M}=\alpha+\beta R V_{t}^{M}+\epsilon_{t+1} \\
& H A R(2): R V_{t+1}^{M}=\alpha+\beta R V_{t}^{M}+\beta R V_{t}^{6 M}+\epsilon_{t+1} \\
& H A R(3): R V_{t+1}^{M}=\alpha+\beta R V_{t}^{M}+\beta R V_{t}^{6 M}+\beta R V_{t}^{1 Y}+\epsilon_{t+1} \\
& H A R(4): R V_{t+1}^{M}=\alpha+\beta R V_{t}^{M}+\beta R V_{t}^{6 M}+\beta R V_{t}^{1 Y}+\beta R V_{t}^{2 Y}+\epsilon_{t+1} \\
& H A R(5): R V_{t+1}^{M}=\alpha+\beta R V_{t}^{M}+\beta R V_{t}^{6 M}+\beta R V_{t}^{1 Y}+\beta R V_{t}^{2 Y}+\beta R V_{t}^{5 Y}+\epsilon_{t+1}
\end{aligned}
$$

The multiperiod volatilities are normalized sums of the one-month realized volatilities.

The six-months' realized volatility is exemplarily given by:

$$
R V_{t}^{6 M}=\frac{1}{6}\left(R V_{t}^{M}+R V_{t-1}^{M}+\ldots+R V_{t-5}^{M}\right)
$$

Despite the simplicity of these models, they are shown to be able to mimic long memory behavior and exhibit good forecasting performance. We form quintile portfolios by sorting the cross-section of stock returns by the memory parameter. We then compute the average adjusted $R^{2}$, F-statistic, and out-of-sample $R_{O O S}^{2}$ for each quintile portfolio. ${ }^{21}$ The calculation of the out-of-sample $R_{O O S}^{2}$ follows ?, and measures the differences in mean squared prediction errors (MSPE) for the predictive model, equations (12)-(16), and the historical mean.

\footnotetext{
${ }^{20}$ Our frequency differs from the one of ?, who relies on daily, weekly, and monthly volatility to forecast the volatility over the next day, week or two weeks. Our goal is different. We are interested in the one month horizon, which is the holding period for our portfolio sorts and the horizon for the cross-sectional regressions.

${ }^{21}$ We report t-statistics of the slope coefficient for HAR(1) and F-statistics for the joint significance of the slope coefficients for the remaining models. For the out-of-sample analysis, the $R_{O O S}^{2}$ for some stocks show extremely bad performance, with values below $-100 \%$ due to large spikes. We winsorize the data at the $1 \%$ and $99 \%$ level to minimize the effect of these outliers. Cleaning the time series of the outliers delivers qualitatively similar results.
} 
The results are reported in Table 6. Panel A shows the adjusted $R^{2}$ of the in-sample predictability regressions. There is a strictly monotonic pattern of explanatory power, which is increasing in the memory parameter. This is supported by the increasing tstatistics and F-statistics in Panel B. Stocks with higher memory parameters exhibit stronger explanatory power and the predictor variables are more statistically significant than stocks with lower memory parameters. Lastly, the $R_{O O S}^{2}$ also show that the outof-sample forecasting performance of long memory stocks is stronger than short memory stocks and exhibits a generally monotonic pattern. A graphical illustration of the results is presented in Figure 1. One can see that the bars are monotonically increasing for all five models in all cases.

We thus show that the memory of stocks is a proxy for predictability, which explains the negative spread returns of the LMS portfolio. At the same time, this exercise validates our estimation approach to memory. Our results are true for both in-sample and out-ofsample, while we allow for various model specifications including short memory processes and long memory mimicking processes. ${ }^{22}$

\section{$5 \quad$ Implications for existing models}

In this section, we discuss the connection between our empirical results and theoretical models of how long memory in volatility is generated for individual stocks using the

\footnotetext{
${ }^{22}$ In this section, we document the intuitive relationship between long memory and predictability of volatility. In additional analyses, we repeat the portfolio sorts and cross-sectional regressions relying on the predictability of volatility as measured by the adjusted $R^{2}$ of the $\operatorname{HAR}(1)$ model. The results are reported in Tables 11 and 12 of the Online Appendix and show evidence for a negative price of predictability. However, the statistical significance is weaker than for long memory and the results for the negative price seem to be explained by the size effect. Hence, long memory seems to be more important and possesses further information compared to known and included control variables. This analysis only considers one of many possibilities to capture the predictability of volatility and its implications for asset pricing while our paper specifically focuses on the memory of stock return volatility. However, this initial test shows the potential of volatility prediction in connection to asset pricing and opens the door for future research.
} 
proposed "agent-based" model of ? and the "interacting agent view" of ?. These models rely on heterogeneity across market agents. ?, ?, and ? also consider markets with heterogenous traders. Motivated by the memory-generating models, we discuss how large and loser stocks in these models differ from small and winner stocks. ${ }^{23}$

\section{$5.1 \quad$ Interacting agent view}

? divide traders in a market into two groups - fundamentalists and chartists - whose interactions are based on the mechanism introduced by ?. The noise traders (chartists) are driven by herd instincts and buy (sell) if they are optimistic (pessimistic). The long memory in volatility is then generated by the interaction of agents with heterogenous beliefs and strategies. The numbers of fundamentalists and chartists are fixed, but transition from optimists to pessimists and vice versa is allowed by a two-state model. They derive an equilibrium distribution with two equilibria where a transition between them has a finite probability. The average time for the transition is denoted as the mean first passage time $T_{0}$. From the ratio of mean first passage time $T_{0}$ and available data observations $T$, conclusions on the memory of the process can be drawn. For higher $T_{0}$ relative to $T$, the memory parameter of squared returns decreases starting with a Hurst exponent close to 1 and converging to 0 for $T>>T_{0}$. The mean first passage time is negatively related to the number of agents $N$ in the market. We divide the cross-section of stock returns into several segments by firm characteristics. The relation of $T$ and $T_{0}$ for each submarket allows for conclusions on the memory of the submarket. We focus on the effect of these two variables, assuming that all other variables are the same for the

\footnotetext{
${ }^{23}$ For these characteristics, we find statistical significance concerning memory parameter spreads for both portfolio sorts and cross-sectional regressions.
} 
two markets. ${ }^{24}$

First, our main analysis shows that stocks with higher market capitalization exhibit longer memory in volatility. ? find that the demand for large and liquid stocks has grown due to the increasing share of the U.S. equity market. Additionally, investment decisions in small stocks are harder for professional managers to justify to sponsors, as argued by ?. Further, ? argues that small stocks exhibit incomplete information. As a result, there is a subset of investors who cannot or does not want to invest into small stocks. All of these findings suggest that the number of investors in large stocks dominates those of small stocks. The larger number of agents for large stocks leads to a higher mean first passage time and hence intuitively to longer memory volatility, as we empirically document.

Second, we find that stocks with longer memory volatility tend to be loser stocks. This result can be explained by the disposition effect, as labeled by ?. The effect states that investors tend to hold their losing stocks too long and sell their winner stocks too soon in financial markets. This effect can be explained in the context of the prospect theory of ? and the mental accounting framework of ?. The results suggest that the number of agents investing in winner stocks tends to decrease while the number for the loser stocks tends to remain constant or even increase. This leads to longer memory for loser stocks, as shown in our main analysis.

\subsection{Agent-based models}

? divides the market into groups according to their investment horizon and hence considers a heterogenous agent framework. The agents rely on past information such as lagged returns, dividend-price ratios, and trend indicators to evaluate the rules for investment

\footnotetext{
${ }^{24}$ The impact of other variables is neglible, since the memory parameter is high for low $T$ relative to $T_{0}$ and always converges to zero for $T \rightarrow \infty$.
} 
decisions. This evaluation varies across agents. Some agents rely only on more recent data, for example only the past six months (short memory investor), while others use thirty years' of data (long memory investor). The trading rules may evolve over time and a Walrasian equilibrium is reached by clearing the market. The author shows that in a market consisting of homogeneous investors (long memory investors only), the price converges to the equilibrium price through the learning mechanism, which results in a short memory process for squared returns. If the market consists of all types of agents (all memory), on the other hand, the price takes large swings from the equilibrium and shows long memory behavior for volatility. Note that long memory can only be generated if the market consists of a mixture of both short-term and long-term investors. The HAR-RV model of ? follows a similar approach in order to mimic long memory by combining both long and more importantly also short-term horizons for the volatility. As argued by ?, short-term investors are influenced by the long-term variance, which again has an impact on the short-term variance while long-term investors are not influenced by changes in short-term volatility. The model can be transferred to parts of the complete market as proxied by the cross-section of U.S. stock returns. We compare the fraction of short- and long-term investors in various markets and draw conclusions on the degree of memory in these markets.

? argue that small firms with little collateral show the highest asymmetry in their risk across recession and expansion states. Their expected returns are thus more sensitive to credit market conditions. ? present similar arguments for small firms being more sensitive to news about the state of the business cycle. This implies that investors in small firms are generally mid- to long-term oriented, while investors of large and better collateralized firms may be both short- and long-term oriented. This is supported by the argument 
from the "interacting agent view model." The higher degree of heterogeneity of large firm investors leads to a higher memory parameter compared to small firms. ${ }^{25}$

? argue that the momentum strategy generates abnormally high returns on average, but at the same time experiences abnormally high losses. This is because the loser stocks embed features of a short call option on the market portfolio. Especially during times of volatile bear markets, past-loser stocks lose a large fraction of their market value and contain high financial leverage. The equity of theses firms is similar to out-of-the money call options on the underlying firm values, which are correlated with the market. This implies that loser stocks are much more sensitive to the state of the market (turbulent vs. calm), which can change quickly. Consequently, the fraction of short-term investors in the market of loser stocks should be larger than in the market of winner stocks, which leads to higher memory estimates for loser stocks. This is what we find empirically.

\section{Extensions and robustness tests}

In this section, we discuss additional analyses of long memory volatility in the crosssection, as well as various robustness tests including alternative estimators and portfolio sorts. We extend our cross-sectional analysis with further control variables. Detailed results are reported in the Online Appendix.

\subsection{Additional control variables}

In Subsection 3.4 we discuss our regression tests including size, book-to-market, momentum, illiquidity, and jumps. We extend these regressions and now also control for further

\footnotetext{
${ }^{25}$ Even though small firm investors are rather short-term oriented, this does not mean there are no long-term investors. The same is true for large firms. Hence we consider the relative proportion of long-term and short-term investors and discuss the degree of heterogeneity.
} 
effects and anomalies, which have been shown to be good predictors of expected returns. More specifically, we add the market beta (BETA), reversal (REV), cokurtosis with the market (CKT), coskewness with the market (CSK), idiosyncratic volatility (IVOL), realized kurtosis (KURT), realized skewness (SKEW), and demand for lottery (MAX) to the analysis. We also include a stock's volatility-of-volatility (Vol-of-Vol). In our empirical analysis we relate the long memory of volatility to the predictability of volatility and uncertainty. We also relate higher volatility predictability to lower uncertainty regarding a stock's risk level. In the literature, uncertainty has been measured by the volatilityof-volatility for both individual stocks and the aggregate market (??). ${ }^{26}$ We calculate the volatility-of-volatility as the five-year rolling window volatility of monthly realized volatility. ${ }^{27}$ We find an average cross-sectional correlation of 0.11 between the degree of long memory volatility of a stock and its volatility-of-volatility. While both are intuitively related to uncertainty, the measures are barely correlated, thus we do not expect that our findings can be explained by the volatility-of-volatility of a stock.

The market beta is estimated from daily return regressions of excess stock returns on an intercept and the market excess return over the examined period. Following ?, idiosyncratic volatility equals the standard deviation of the residuals from the same regression as for the market beta, but additionally includes the size and book-to-market factors of ?. The short-term reversal at the end of a month is defined as the return of that month following ?. The coskewness and cokurtosis of a stock at the end of a month is estimated from the daily returns in that month following ?. The kurtosis and skewness of a stock at the end of a month is given by the sample kurtosis and skewness estimated

\footnotetext{
${ }^{26}$ Both studies investigate the asset pricing implication of the volatility-of-volatility and find a negative price, just as we find for long memory.

${ }^{27}$ It is not possible to compute the measure of ? for our sample since they rely on options data of individual stocks, which are available starting in 1996 from OptionMetrics. Our approach for calculating the volatility-of-volatility closely follows the approach for our long memory estimates.
} 
from the daily returns in that month. Lastly, the demand for lottery is given by the maximum total daily return observation of a month (?).

Table 7 presents the results of the cross-sectional regressions. ${ }^{28}$ Models 7 to 15 show the time-series averages of the additional coefficients in multiple regressions. Most importantly, the risk premium of the long memory volatility remains negative and statistically significant for all additional control variables, varying from -0.0043 to -0.0036 . The signs of statistically significant risk premia for variables besides long memory are generally consistent with the literature. ? find that portfolios with higher betas have lower alphas and Sharpe ratios than portfolios of low-beta assets. ? show that buying stocks with low realized skewness and selling stocks with high realized skewness generates statistically significant and positive excess returns at a weekly frequency while there is no clear relationship for realized kurtosis. The negative and statistically significant premium for idiosyncratic volatility is consistent with the results of ?. ? argue that investors are willing to pay more for stocks that exhibit extreme positive returns. As a consequence, these stocks exhibit lower future returns, which is consistent with the negative premium we find. Model 16 includes the memory parameter and all additional control variables in this section while Model 17 presents the kitchen sink regression. The coefficient of the memory parameter remains statistically significant at the $5 \%$ level or lower.

We control for two additional variables: aggregate long memory and aggregate volatility. Following?, we rely on changes in the volatility index (VIX) as a proxy for innovations in aggregate volatility. The VIX presents the implied volatility of a S\&P 100 index contract over the next 30 days, which is at-the-money. Since the data goes back only until 1986, we rely on U.S. stock market volatility following ? for the time before. We com-

\footnotetext{
${ }^{28}$ We also report mean values of each control variable in quintile portfolios, which are sorted by long memory volatility. The results are presented in Table 8.
} 
pute the monthly standard deviation of the daily market returns and normalize the time series of monthly return volatilities to the same mean and variance as the VIX when they overlap from 1986 until 2015. For aggregate long memory, we follow the approach in our main analysis and apply the GPH estimator and the bandwidth parameter $m=N^{0.5}$ to squared market returns in the most recent 60 months. For each stock, we then estimate sensitivities to aggregate long memory and volatility (?):

$$
r_{i, t}-r_{f, t}=\beta_{0}+\beta_{i, M k t} M K T_{t}+\beta_{i, A F} \Delta A F_{t}+\epsilon_{i, t},
$$

where $M K T$ is the market excess return, $\triangle A F$ describes the innovations in the aggregate factor (long memory or volatility), $\beta_{i, M k t}$ and $\beta_{i, A F}$ are loadings on the market risk and aggregate factor, respectively, and $\epsilon$ is the error term. For both, aggregate long memory and volatility, we estimate the loadings in time-series regressions using a rolling window of 60 observations.

Lastly, we want to examine the difference between the predictability of volatility and the level of volatility itself. By further controlling for the level of volatility, we can state that even conditional on the same level of volatility, investors prefer stocks with longer memory volatility over shorter memory volatility due to their higher predictability. We include the level of the volatility at the end of the month as measured by the variance of daily returns in that month.

We then repeat our regression tests and also include the loadings on aggregate long memory and volatility, as well as the level of variance in the vector $X_{i, t}$. Table 9 reports the results. The first three columns present the results when extending our control variables from Subsection 3.4, while columns four, five and six present the results when we include the control variables discussed above. The coefficient associated with the risk premium 
of long memory remains negative and statistically significant for all model specifications. Our findings thus show that aggregate volatility, aggregate long memory, and the level of volatility (variance) cannot explain our results.

\subsection{Long memory volatility and industries}

In Section 3, we consider different firm characteristics and how they are able to explain the memory parameter of volatility in the cross-section of U.S. returns. We find that higher memory parameters can be related to large, loser stocks and stocks with fewer jumps. In this section, we investigate whether firms in certain industries possess higher or lower memory parameters. More specifically, we use the twelve industry portfolio identifiers obtained from Kenneth French's data library. The industries are Consumer Non-Durables, Consumer Durables, Manufacturing, Energy, Chemicals, Business Equipment, Telecommunication, Utilities, Shops, Healthcare, Money \& Finance, and Others. We apply the GPH estimator and a bandwidth parameter of $m=N^{0.5}$ as in our main analysis. Table 13 of the Online Appendix reports the results. The mean and median are very close to the value for the complete cross-section (0.22). Since the degree of memory is similar for all industries, industry codes, unlike firm characteristics, are not able to explain the cross-sectional variation of the memory parameter.

\subsection{Fama-French portfolios}

In Section 3, we sort stocks by their memory parameter and investigate the average firm characteristics of quintile portfolios. In this subsection, we validate our results by comparing the memory of Fama-French decile portfolios, which are sorted by size, bookto-market or momentum. There are two major differences with this approach. First, 
instead of sorting by the memory parameter, stocks are sorted by their firm characteristics. Second, we consider decile instead of quintile portfolios. ${ }^{29}$ The portfolio returns are obtained from Kenneth French's data library. We apply the GPH estimator with the bandwidth parameter of $m=N^{0.5}$ as in our main analysis and report the memory parameter for each decile portfolio and the high-minus-low $(D 10-D 1)$ in Table 14 of the Online Appendix. Consistent with our main results, portfolios with larger size, higher book-to-market, and worse prior performance exhibit higher memory parameters. ${ }^{30}$ The book-to-market (momentum) portfolios demonstrate a monotonically increasing (decreasing) pattern in memory.

\subsection{Estimation of the memory parameter}

For our main analysis, we follow the literature and choose the ad hoc bandwidth parameter of $m=N^{0.5}$. We repeat the estimation using a bandwidth parameter of $m=N^{0.6}$, $m=N^{0.7}$, and $m=N^{0.8}$ and alternative estimators and report the results in Tables 15 , 16, and 17 of the Online Appendix. ${ }^{31}$

In Panels A, B, and $\mathrm{C}$ of Table 15, we report the portfolio sorts for the cross-section of U.S. returns using the GPH estimator and alternative parameters. We find that sorting by the memory parameter and holding stocks with long memory and selling stocks with short memory still generates negative excess returns. Using the alternative bandwidth parameters $m=N^{0.6}, m=N^{0.7}$, and $m=N^{0.8}$ leads to returns of $-1.80 \%,-2.71 \%$, and $-2.32 \%$ per annum, respectively. Adjusting for the additional risk factors of the ?

\footnotetext{
${ }^{29}$ The results for the Fama-French quintile portfolios are qualitatively similar.

${ }^{30}$ The magnitude of the memory parameters are somewhat higher than in our main analysis. This is because we here use the complete time series of daily returns over more than 60 years, compared to the 5 years in our main analysis.

${ }^{31}$ These alternative bandwidth parameters are the most common choices in the literature, see ?, ?, ?, ?, ?, among others, and include the MSE-optimal one for the GPH estimator.
} 
five-factor model leads to significant alphas of similar magnitudes as in our main analysis.

Further, we apply the GPH estimator to the absolute returns rather than the squared returns as in our main analysis (?). The results are reported in Panel D and are consistent with our main findings. Stocks with a short memory earn on average $2.94 \%$ per annum more than stocks with a long memory. This spread return is statistically significant at the $1 \%$ level and remains significant when controling for the ? risk factors.

A commonly used alternative approach to estimate long memory is the Local Whittle (LW) estimator. We repeat the estimation with the LW estimator and the same bandwidth parameter as in our main results, $m=N^{0.5}(?)$. The results are provided in Table 16. For the portfolio sorts, we find a negative spread return of $2.09 \%$ for the LMS portfolio which is statistically significant at the $5 \%$ level (Panel A). The ? five-factor alpha with a value of $-3.21 \%$ is statistically significant as well. In addition, we apply the LW estimator with bandwidth parameters of $m=N^{0.6}, m=N^{0.7}$, and $m=N^{0.8}$ to the squared returns and a bandwidth parameter of $m=N^{0.5}$ to the absolute returns. Panels $\mathrm{B}$ to $\mathrm{E}$ report the results. The spread returns are all negative, varying from $-1.82 \%$ to $-3.03 \%$, and the ? five-factor alphas vary from $-2.54 \%$ to $-3.93 \%$, while all returns and risk-adjusted returns are statistically significant.

Table 17 reports the coefficient estimates from the cross-sectional regressions in equation (11) using the alternative long memory estimator and bandwidths. We rely on simple regressions where individual stock returns are regressed on the long memory parameter in Panel A and multiple regressions where we additionally include size, book-to-market, momentum, illiquidity, and the BNS jump test statistic as explanatory variables. The results are consistent with our main analysis. For the simple regressions, we find that long memory is negatively priced in the cross-section with a risk premium estimate varying 
from -0.0104 to -0.0039 , depending on the estimator and bandwidth, which is statistically significant. Including the control variables slightly changes the magnitude of the long memory premium but they remain statistically significant. In addition, we find a negative (positive) price for the size (book-to-market ratio and momentum) of a stock which is consistent with both our main analysis and the literature.

\subsection{Holding period returns}

In our main analysis, portfolios are rebalanced monthly and held for one month. We next examine whether the negative risk premium associated with long memory volatility persists for longer holding periods. For each month, we sort all stocks into quintile portfolios where stocks with the lowest memory parameter are in the first quintile and stocks with the highest memory parameter are in the fifth quintile. Excess returns of the portfolios are tracked over the subsequent one, two, three, four, and five years. To account for the overlapping returns, we adjust the standard errors following ?, using lags according to the return horizon expressed in months.

The results are reported in Table 18 of the Online Appendix. Average returns and ? risk-adjusted returns for the one-, two-, three-, four-, and five-year holding periods are reported in Panels A-E. The annualized mean returns are of similar magnitude as for the one-month holding period. The LMS spreads are $-1.88 \%,-1.93 \%,-1.88 \%,-1.90 \%$, and $-1.91 \%$, respectively, and are all statistically significant at the $5 \%$ level or lower. The risk-adjusted returns only change slightly, and vary from $-1.66 \%$ to $-2.29 \%$ and are generally statistically significant. 


\subsection{High-frequency data}

We repeat our analysis, but rely on high-frequency data instead of daily returns. We obtain five-minute returns for the S\&P 500 constituents for the 1996-2015 period from Thomson Reuters Tick History. Our choice of the sample period and stocks is restricted by their availability. The data are cleaned following ?. ? argue that high-frequency data should always result in a more accurate estimate when used correctly due to the basic statistical principle that more data are always better. ? show that the high-frequency data allow for a superior and nearly unbiased estimation of the long memory parameter using five-minute return observations. We apply the GPH estimator and a bandwidth parameter of $m=N^{0.5}$ to a month of five-minute returns, which is $1,738(=22 * 79)$ data points per estimation window. This window is comparable to eight years of daily observations.

The results are reported in Table 19 of the Online Appendix. We find a negative return of $-8.83 \%$ for the LMS portfolio, which is statistically significant at the $1 \%$ level. Controling for additional risk factors generally slightly mitigates the risk premium but the alphas remain significant. The results in this section thus confirm our main results and show that the negative risk premium is not dependent on the source and frequency of data and the sample period. We implicitly investigate four subsamples and thus show that our main results are robust against various sample periods. Our choice of subsamples is motivated by data availability. The longest period from 1926 to 2015 is chosen according to the availability of the CRSP stock data. We control for ? (?) risk factors, which are available from 1963 to 2015 (1967 to 2015). Lastly, we also investigate the most recent 20 years from 1996 to 2015, which is chosen due to the availability of high-frequency data from Thomson Reuters Tick History. 


\subsection{Illiquidity, missing observations, and long memory}

One might wonder whether the relationship between the size or jumps of a stock and its degree of memory is mechanical since volatility measures may be computed with smaller estimation error for high market capitalization and hence liquid stocks, which translates into a higher persistence of the volatility dynamics. ? show that the detection of jumps may be biased by the presence of missing returns, which is more common for illiquid stocks. In this subsection, we control for these potential issues and show that our results for size and jumps are not due to such reasons.

First, we plot the time series averages of the size and degree of memory of a stock in Figure 2 of the Online Appendix which shows that the results are unlikely driven by strong outliers. In a linear regression (when excluding the 1st and 99th quantiles for both variables) size is a strongly significant (and positive) explanatory variable for memory, with a t-statistic that is larger than 19.0 (46.0).

Second, we repeat the portfolio sorts and exclude the most illiquid stocks from the analysis to see whether our results still hold when considering only liquid stocks. To do so, we measure illiquidity by the proportion of days with zero or missing returns. The results are presented in Table 20 in the Online Appendix. Panel A is a replication of the main results. In Panel B (D), we only consider the $50 \%$ of the stocks with the least zero (missing) returns while in Panel C (E) we require a stock to have zero (missing) returns on less than $10 \%$ of the days. The results are consistent (although slightly weaker) with our main findings for the entire sample and emphasize that the positive relationship we find between size/jumps and the degree of memory also holds for liquid stocks.

Third, we repeat the cross-sectional regressions as for the portfolio sorts and exclude illiquid stocks measured by the proportion of zero or missing returns. Table 21 of the 
Online Appendix shows the estimation results for the slope coefficients of Size and BNS, which are very similar as those for the complete sample.

\section{Conclusion}

In this paper, we provide new information and insights into the asset pricing implications of long memory in stock return volatility. Using portfolio sorts and cross-sectional regressions, we analyze how the degree of long memory of a firm's return volatility can be explained by its size, book-to-market, prior performance or jumps. Based on theoretical models, we discuss how long memory is generated in high market capitalization (winner) stocks compared to low market capitalization (loser) stocks. We estimate a cross-sectional price of long memory of $-4.7 \%$ per annum. This estimate is robust to controling for size, value, momentum, liquidity effects, and more. We relate the compensation for holding short memory stocks to higher risk, which is given by the low predictability of short memory stocks. Our results are robust against different variations of the estimation approach and the examined models. 
Figure 1: Predictability of quintile portfolios
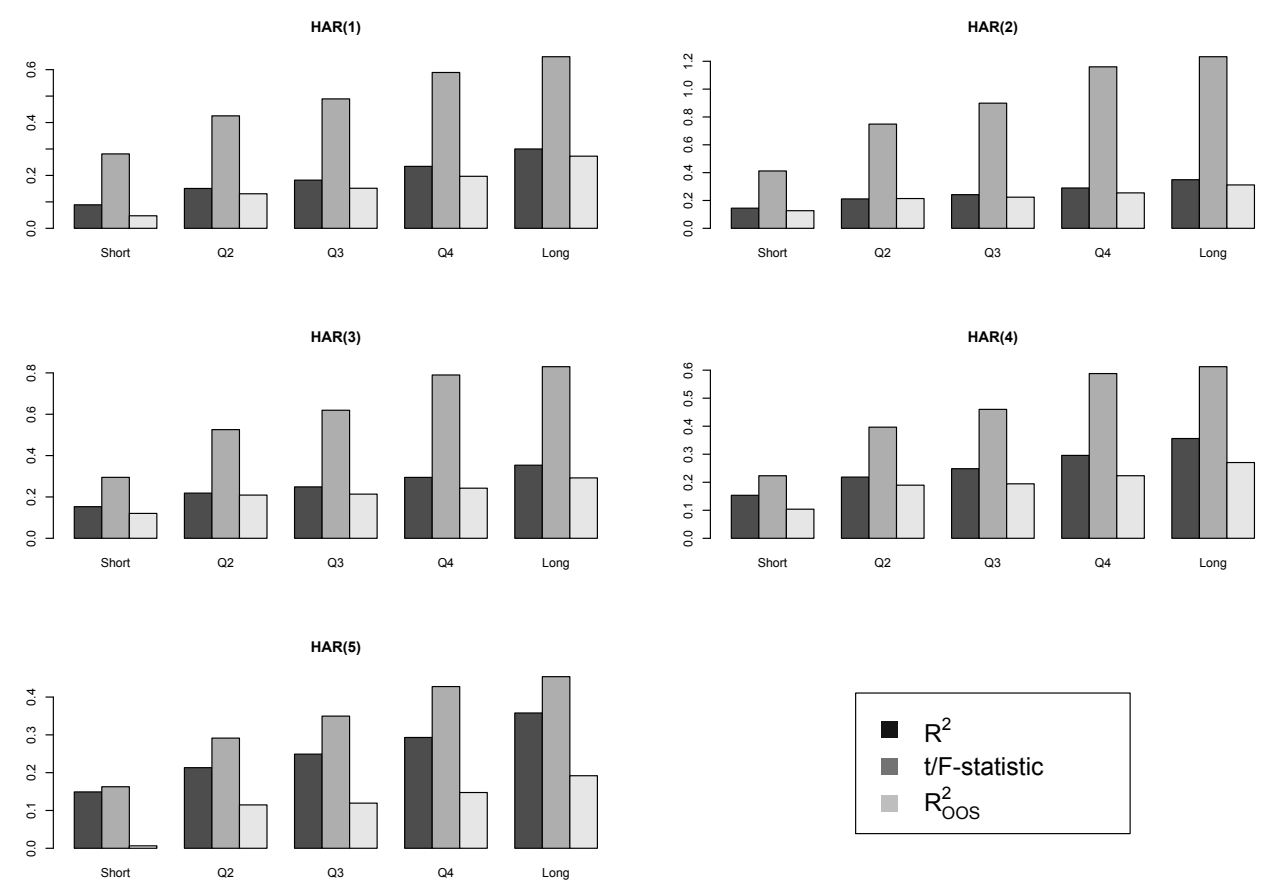

- $\mathrm{R}^{2}$

- $\mathrm{t} / \mathrm{F}$-statistic

$\mathrm{R}_{\mathrm{OOS}}^{2}$

This figure reports adjusted $R^{2}$, F-statistics, and $R_{O O S}^{2}$ for quintile portfolios of the crosssection of U.S. stock returns. For a better presentation, the test statistics are all divided by 100 . 
This table presents summary statistics for the memory estimates of individual stocks' volatility. The memory parameter is estimated with the GPH estimator and a bandwidth parameter of $m=N^{0.5}$. In our sample, we have an average number of 2480 long memory estimates per month. AR(1) stands for the cross-sectional average of first-order autocorrelation coefficients. SD stands for the standard deviation. The middle panel reports selected quantiles of the averages. t-statistic reports the mean t-statistic. Sign. at $5 \%$ reports the proportion of significant long memory estimates, while the remainder of the last column reports the proportion of the memory parameter being in a certain interval.

\begin{tabular}{lllllr}
\hline \multicolumn{2}{c}{ Descriptive } & \multicolumn{2}{c}{ Quantiles } & \multicolumn{2}{c}{ Memory } \\
\hline AR $(1)$ & 0.87 & $5 \%$ & 0.04 & t-statistic & 23.34 \\
Mean & 0.22 & $25 \%$ & 0.15 & Sign. at $5 \%$ & 0.96 \\
SD & 0.12 & Median & 0.22 & $-0.5<d<0.0$ & 0.03 \\
Skewness & 0.40 & $75 \%$ & 0.29 & $0.0<d<0.5$ & 0.95 \\
Kurtosis & 1.48 & $95 \%$ & 0.43 & $0.5<d<1$ & 0.02 \\
\hline \hline
\end{tabular}


Table 2: Portfolio sorts and characteristics

This table presents the firm characteristics of portfolios sorted by the memory of volatility. The memory parameter is estimated with the GPH estimator and a bandwidth parameter of $m=N^{0.5}$. We sort stocks each month for the 1950 to 2015 period and form and hold the portfolio for one month. We report the average long memory parameter, size, momentum and illiquidity, BNS statistic, and BNS indicator function of quintile portfolios. The Q5Q1 column reports the averages for the long memory minus short memory portfolio (LMS) with the associated t-statistics in parentheses.

\begin{tabular}{lrrrrrrr}
\hline & \multicolumn{1}{c}{ Q1 } & \multicolumn{1}{c}{ Q2 } & \multicolumn{1}{c}{ Q3 } & \multicolumn{1}{c}{ Q4 } & \multicolumn{1}{c}{ Q5 } & Q5-Q1 (LMS) & \\
\hline Memory & 0.0044 & 0.1295 & 0.2118 & 0.2975 & 0.4471 & 0.4427 & {$[202.76]$} \\
Size & 11.6610 & 11.8630 & 12.0161 & 12.1707 & 12.3560 & 0.6950 & {$[23.34]$} \\
Book-to-Market & 0.8934 & 0.9168 & 0.8993 & 0.8758 & 0.8996 & 0.0062 & {$[0.60]$} \\
Momentum & 0.1681 & 0.1558 & 0.1522 & 0.1483 & 0.1284 & -0.0397 & {$[-14.27]$} \\
Illiquidity & 0.0044 & 0.0040 & 0.0038 & 0.0040 & 0.0055 & 0.0010 & {$[3.92]$} \\
BNS & -0.1994 & -0.0620 & -0.0255 & -0.0110 & 0.0036 & 0.2030 & {$[12.50]$} \\
BNS-I & 0.0177 & 0.0126 & 0.0106 & 0.0087 & 0.0074 & -0.0103 & {$[-24.26]$} \\
\hline \hline
\end{tabular}


Table 3: Cross-sectional regression

This table presents the results from cross-sectional regressions for the 1950-2015 period. for each month, we regress the memory parameter of the cross-section on size, bookto-market, momentum, illiquidity and BNS. The memory parameter is estimated with the GPH estimator and a bandwidth parameter of $m=N^{0.5}$. We report the average $\beta$ coefficients and the standard errors in parentheses. Model 1 excludes any jump measures. Model 2 includes the BNS jump statistic while Model 3 includes the BNS jump indicator. Stars indicate significance: ${ }^{*}$ significant at $p<0.10 ;{ }^{* *} p<0.05 ;{ }^{* *} p<0.01$.

\begin{tabular}{lccccccc}
\hline & Intercept & Size & Book-to-Market & Momentum & Illiquidity & BNS & BNS-I \\
\hline Model 1 & $0.0292^{* * *} 0.0160^{* * *}$ & $0.0019^{* * *}$ & $-0.0186^{* * *}$ & 0.3126 & & \\
& $(0.0061)(0.0006)$ & $(0.0006)$ & $(0.0013)$ & $(0.2696)$ & & \\
Model 2 & $0.0286^{* * *} 0.0161^{* * *}$ & $0.0017^{* * *}$ & $-0.0184^{* * *}$ & 0.3720 & $0.0052^{* * *}$ & \\
& $(0.0061)(0.0006)$ & $(0.0006)$ & $(0.0013)$ & $(0.2738)$ & $(0.0005)$ & \\
Model 3 & $0.0301^{* * *} 0.0160^{* * *}$ & $0.0018^{* * *}$ & $-0.0185^{* * *}$ & 0.3701 & & $-0.0491^{* * *}$ \\
& $(0.0061)(0.0006)$ & $(0.0006)$ & $(0.0013)$ & $(0.2754)$ & $(0.0025)$ \\
\hline \hline
\end{tabular}


Table 4: Sorted portfolio returns

This table reports average returns and risk-adjusted returns of equally weighted quintile portfolios for the 1926-2015 period. Each month, stocks are sorted by the degree of long memory in volatility and we track the portfolio returns over the subsequent month. The memory parameter is estimated with the GPH estimator and a bandwidth parameter of $m=N^{0.5}$. The one-month-ahead portfolio returns are regressed on risk factors in the Capital Asset Pricing Model (CAPM), the ? three-factor model (FF3), the ? five-factor model (period starts in 1963) (FF5), and the ? q-model (period starts in 1967) (HXZ). The corresponding alphas are reported. We report ? standard errors using lags equal to the return horizon in parentheses. Stars indicate significance: ${ }^{*}$ significant at $p<0.10$; ${ }^{* *} p<0.05 ;{ }^{* * *} p<0.01$.

\begin{tabular}{lcccccc}
\hline & Q1 & Q2 & Q3 & Q4 & Q5 & Q5-Q1 (LMS) \\
\hline Mean return & $0.1357^{* * *}$ & $0.1288^{* * *}$ & $0.1344^{* * *}$ & $0.1263^{* * *}$ & $0.1186^{* * *}$ & $-0.0171^{* *}$ \\
& $(0.0334)$ & $(0.0326)$ & $(0.0343)$ & $(0.0346)$ & $(0.0356)$ & $(0.0086)$ \\
\hline CAPM & $0.0385^{* * *}$ & $0.0328^{* * *}$ & $0.0337^{* * *}$ & $0.0238^{* *}$ & 0.0162 & $-0.0223^{* * *}$ \\
FF3 & $(0.0125)$ & $(0.0115)$ & $(0.0110)$ & $(0.0103)$ & $(0.0108)$ & $(0.0083)$ \\
& $0.0136^{* *}$ & $0.0103^{* *}$ & $0.0084^{*}$ & -0.0016 & $-0.0111^{*}$ & $-0.0247^{* * *}$ \\
FF5 & $(0.0062)$ & $(0.0051)$ & $(0.0048)$ & $(0.0048)$ & $(0.0062)$ & $(0.0077)$ \\
& $0.0238^{* *}$ & $0.0146^{*}$ & $0.0137^{*}$ & 0.0045 & -0.0046 & $-0.0284^{* * *}$ \\
HXZ & $(0.0108)$ & $(0.0087)$ & $(0.0076)$ & $(0.0075)$ & $(0.0095)$ & $(0.0099)$ \\
& $0.0450^{* * *}$ & $0.0340^{* * *}$ & $0.0335^{* * *}$ & $0.0270^{* *}$ & 0.0198 & $-0.0252^{*}$ \\
\hline \hline
\end{tabular}


Table 5: Fama-MacBeth regression results

This table reports results from ? regressions for the 1950-2015 period. For each month, excess stock returns are regressed on lagged firm characteristics including the memory parameters, market capitalization (Size), book-to-market values, prior returns (Momentum), illiquidity, and jump statistics (BNS). The memory parameter is estimated with the GPH estimator and a bandwidth parameter of $m=N^{0.5}$. We report ? standard errors using lags equal to the return horizon in parentheses. Stars indicate significance: * significant at $p<0.10 ;{ }^{* *} p<0.05 ;{ }^{* * *} p<0.01$.

\begin{tabular}{|c|c|c|c|c|c|c|c|}
\hline & Model 1 & Model 2 & Model 3 & Model 4 & Model 5 & Model 6 & Model 7 \\
\hline \multirow[t]{2}{*}{ Intercept } & $0.0091^{* *}$ & * $0.0144^{* * *}$ & * $0.0075^{* *}$ & $* 0.0076^{* *}$ & ${ }^{*} 0.0087^{* *}$ & $* 0.0091^{* *}$ & ** $0.0106^{*}$ \\
\hline & $(0.0025)$ & $(0.0051)$ & $(0.0025)$ & $(0.0025)$ & $(0.0025)$ & $(0.0025)$ & $(0.0056)$ \\
\hline \multirow[t]{2}{*}{ Long Memory } & $-0.0039^{* *}$ & $-0.0021^{*}$ & $-0.0038^{* *}$ & $-0.0038^{* *}$ & $-0.0044^{* *}$ & $*-0.0043^{* *}$ & ${ }^{*}-0.0024^{* *}$ \\
\hline & $(0.0016)$ & $(0.0012)$ & $(0.0016)$ & $(0.0016)$ & $(0.0016)$ & $(0.0016)$ & $(0.0011)$ \\
\hline \multirow[t]{2}{*}{ Size } & & $-0.0006^{*}$ & & & & & -0.0005 \\
\hline & & $(0.0003)$ & & & & & $(0.0003)$ \\
\hline \multirow[t]{2}{*}{ Book-to-Market } & & & $0.0019^{* *}$ & & & & $0.0024^{* * *}$ \\
\hline & & & $(0.0005)$ & & & & $(0.0006)$ \\
\hline \multirow[t]{2}{*}{ Momentum } & & & & $0.0067^{* *}$ & & & $0.0095^{* * *}$ \\
\hline & & & & $(0.0016)$ & & & $(0.0013)$ \\
\hline \multirow[t]{2}{*}{ Illiquidity } & & & & & $0.2010^{* *}$ & & 0.0991 \\
\hline & & & & & $(0.1010)$ & & $(0.1768)$ \\
\hline \multirow[t]{2}{*}{ BNS } & & & & & & $0.0024^{* *}$ & $0.0020^{* * *}$ \\
\hline & & & & & & $(0.0004)$ & $(0.0003)$ \\
\hline
\end{tabular}


Table 6: Long memory and predictability

This table reports results of predictive regressions. We run heterogenous autoregressive regressions of the monthly realized variance for each stock including the previous one, six, twelve, twenty-four, and sixty observations. We form quintile portfolios where stocks with the lowest memory parameter are in the first quintile and stocks with the highest memory parameter in the fifth quintile portfolio. We report average adjusted $R^{2}$ in Panel $\mathrm{A}$, average t-statistics and F-statistics in Panel $\mathrm{B}$, and out-of-sample $R^{2}$ in Panel C.

\begin{tabular}{lrrrrr}
\hline \multicolumn{7}{c}{ Q1 } & Q2 & Q3 & Q4 & Q5 \\
\hline Panel A: Adjusted & $R^{2}$ & & & \\
\hline HAR(1) & 0.0888 & 0.1507 & 0.1822 & 0.2343 & 0.3000 \\
HAR(2) & 0.1447 & 0.2111 & 0.2418 & 0.2897 & 0.3491 \\
HAR(3) & 0.1529 & 0.2185 & 0.2486 & 0.2946 & 0.3536 \\
HAR(4) & 0.1535 & 0.2184 & 0.2484 & 0.2958 & 0.3561 \\
HAR(5) & 0.1491 & 0.2132 & 0.2490 & 0.2931 & 0.3579 \\
\hline Panel B: & T-statistic/F-statistic & & \\
\hline HAR(1) & 5.6276 & 8.5058 & 9.7878 & 11.7858 & 12.9780 \\
HAR(2) & 41.2025 & 74.8700 & 89.9142 & 116.0092 & 123.2804 \\
HAR(3) & 29.4787 & 52.5572 & 61.9348 & 78.9834 & 82.9948 \\
HAR(4) & 22.3186 & 39.6614 & 46.0103 & 58.7847 & 61.2399 \\
HAR(5) & 16.2773 & 29.1439 & 34.9617 & 42.7776 & 45.3960 \\
\hline Panel C: & $R_{\text {OOS }}^{2}$ & \multicolumn{5}{c}{} & \\
\hline HAR(1) & 0.0474 & 0.1306 & 0.1515 & 0.1967 & 0.2729 \\
HAR(2) & 0.1266 & 0.2139 & 0.2237 & 0.2546 & 0.3117 \\
HAR(3) & 0.1203 & 0.2090 & 0.2136 & 0.2424 & 0.2921 \\
HAR(4) & 0.1039 & 0.1896 & 0.1944 & 0.2233 & 0.2704 \\
HAR(5) & 0.0064 & 0.1147 & 0.1194 & 0.1475 & 0.1919 \\
\hline \hline
\end{tabular}


Table 7: Fama-MacBeth regressions: additional control variables

This table reports results from ? regressions for the 1950-2015 period. Each month, excess stock returns are regressed on lagged firm characteristics including, memory parameters, market capitalization (Size), book-to-market values, prior returns (Momentum), illiquidity, and jump statistics (BNS). We further control for Beta, Cokurtosis (CKT), Coskewness (CSK), idiosyncratic volatility (IVOL), kurtosis (KURT), skewness (SKEW), demand for lottery (MAX), and volatility of volatility (Vol-of-Vol). We report ? standard errors using lags equal to the return horizon in parentheses. Stars indicate significance: ${ }^{*}$ significant at $p<0.10 ;{ }^{* *} p<0.05$; ${ }^{* * *} p<0.01$.

\begin{tabular}{|c|c|c|c|c|c|c|c|c|c|c|c|c|c|c|c|c|c|}
\hline & Model 1 & Model 2 & Model 3 & Model 4 & Model 5 & Model 6 & Model 7 & Model 8 & Model 9 & Model 10 & Model $11 \quad 1$ & Model $12 \quad 1$ & Model $13 \quad 1$ & Model $14 \quad \mathrm{l}$ & Model $15 \quad 1$ & Model $16 \quad 1$ & Model 17 \\
\hline Intercept & $\begin{array}{l}0.0091^{* * * *} \\
(0.0025)\end{array}$ & $\begin{array}{c}{ }^{*} \\
0.0144^{* *} \\
\\
(0.0051)\end{array}$ & $\begin{array}{c}* 0.0075^{* * *} \\
(0.0025)\end{array}$ & $\begin{array}{c}* 0.0076^{* * *} \\
(0.0025)\end{array}$ & $\begin{array}{c}* 0.0087^{* * *} \\
(0.0025)\end{array}$ & $\begin{array}{l}0.0091^{* * *} \\
(0.0025)\end{array}$ & $\begin{array}{c}0.0096^{* * *} \\
(0.0027)\end{array}$ & $\begin{array}{c}* 0.0095^{* *} \\
(0.0024)\end{array}$ & $\begin{array}{ll}* * & 0.0087^{* * *} \\
& (0.0026)\end{array}$ & $\begin{array}{ll} & 0.0089^{* * *} \\
& (0.0026)\end{array}$ & $\begin{array}{ll} & 0.0116^{* * *} \\
& (0.0019)\end{array}$ & $\begin{array}{ll} & 0.0114^{* * *} \\
& (0.0025)\end{array}$ & $\begin{array}{l}0.0096 \text { *** } \\
(0.0025)\end{array}$ & $\begin{array}{l}0.0122^{* * *} \\
(0.0021)\end{array}$ & $\begin{array}{l}0.0089^{* * *} \\
(0.0017)\end{array}$ & $\begin{array}{l}0.0106^{* * *} \\
(0.0019)\end{array}$ & $\begin{array}{c}0.0267^{* * *} \\
(0.0040)\end{array}$ \\
\hline Long Memory & $\begin{array}{c}-0.0039^{* *} \\
(0.0016)\end{array}$ & $\begin{array}{r}-0.0021^{*} \\
(0.0012)\end{array}$ & $\begin{array}{c}-0.0038^{* *} \\
(0.0016)\end{array}$ & $\begin{array}{c}-0.0038^{* *} \\
(0.0016)\end{array}$ & $\begin{array}{c}-0.0044^{* * *} \\
(0.0016)\end{array}$ & $\begin{array}{c}-0.0043^{* * *} \\
(0.0016)\end{array}$ & $\begin{array}{c}* 0.0040^{* *} \\
(0.0017)\end{array}$ & $\begin{array}{c}-0.0037^{* *} \\
(0.0016)\end{array}$ & $\begin{array}{c}* 0.0036^{* *} \\
(0.0016)\end{array}$ & $\begin{array}{c}-0.0037^{* *} \\
(0.0016)\end{array}$ & $\begin{array}{c}-0.0042^{* * *} \\
(0.0014)\end{array}$ & $\begin{array}{c}{ }^{*}-0.0043^{* * *} \\
(0.0017)\end{array}$ & $\begin{array}{c}{ }^{*}-0.0039^{* *} \\
(0.0016)\end{array}$ & $\begin{array}{c}-0.0041^{* * *} \\
(0.0015)\end{array}$ & $\begin{array}{c}-0.0038^{* * *} \\
(0.0014)\end{array}$ & $\begin{array}{c}-0.0041^{* * *} \\
(0.0013)\end{array}$ & $\begin{array}{c}{ }^{*}-0.0021^{* *} \\
(0.0010)\end{array}$ \\
\hline Size & & $\begin{array}{r}-0.0006^{*} \\
(0.0003)\end{array}$ & & & & & & & & & & & & & & & $\begin{array}{c}-0.0013^{* * *} \\
(0.0002)\end{array}$ \\
\hline Book-to-Market & & & $\begin{array}{l}0.0019^{* * *} \\
(0.0005)\end{array}$ & & & & & & & & & & & & & & $\begin{array}{l}0.0012^{* *} \\
(0.0005)\end{array}$ \\
\hline Momentum & & & & $\begin{array}{l}0.0067^{* * *} \\
(0.0016)\end{array}$ & & & & & & & & & & & & & $\begin{array}{l}0.0096^{* * *} \\
(0.0013)\end{array}$ \\
\hline Illiquidity & & & & & $\begin{array}{c}0.2010^{* *} \\
(0.1010)\end{array}$ & & & & & & & & & & & & $\begin{array}{l}0.4686^{* *} \\
(0.1836)\end{array}$ \\
\hline BNS & & & & & & $\begin{array}{l}0.0024^{* * *} \\
(0.0004)\end{array}$ & & & & & & & & & & & $\begin{array}{c}-0.0001 \\
(0.0003)\end{array}$ \\
\hline Beta & & & & & & & $\begin{array}{c}-0.0510^{* * *} \\
(0.0042)\end{array}$ & & & & & & & & & $\begin{array}{c}-0.0006 \\
(0.0005)\end{array}$ & $\begin{array}{c}-0.0006 \\
(0.0006)\end{array}$ \\
\hline REV & & & & & & & & $\begin{array}{c}-0.0005 \\
(0.0005)\end{array}$ & & & & & & & & $\begin{array}{c}-0.0577^{* * *} \\
(0.0043)\end{array}$ & $\begin{array}{c}{ }^{*}-0.0395^{* * *} \\
(0.0037)\end{array}$ \\
\hline CKT & & & & & & & & & $\begin{array}{c}0.0000 \\
(0.0005)\end{array}$ & & & & & & & $\begin{array}{c}0.0007 \\
(0.0005)\end{array}$ & $\begin{array}{l}0.0011^{* * *} \\
(0.0004)\end{array}$ \\
\hline CSK & & & & & & & & & & $\begin{array}{c}-0.0005 \\
(0.0008)\end{array}$ & & & & & & $\begin{array}{c}0.0003 \\
(0.0007)\end{array}$ & $\begin{array}{c}-0.0010 \\
(0.0007)\end{array}$ \\
\hline IVOL & & & & & & & & & & & $\begin{array}{c}-0.1483^{* * *} \\
(0.0447)\end{array}$ & & & & & $\begin{array}{c}-0.0725 \\
(0.0598)\end{array}$ & $\begin{array}{c}-0.2892^{* * *} \\
(0.0535)\end{array}$ \\
\hline KURT & & & & & & & & & & & & $\begin{array}{c}-0.0006^{* * *} \\
(0.0001)\end{array}$ & & & & $\begin{array}{c}-0.0003^{* *} \\
(0.0001)\end{array}$ & $\begin{array}{c}-0.0002^{* *} \\
(0.0001)\end{array}$ \\
\hline SKEW & & & & & & & & & & & & & $\begin{array}{c}-0.0020^{* * *} \\
(0.0003)\end{array}$ & & & $\begin{array}{l}0.0014^{* * *} \\
(0.0003)\end{array}$ & $\begin{array}{c}0.0009^{* * *} \\
(0.0003)\end{array}$ \\
\hline MAX & & & & & & & & & & & & & & $\begin{array}{c}-0.0610^{* * *} \\
(0.0112)\end{array}$ & & $\begin{array}{c}-0.0159 \\
(0.0164)\end{array}$ & $\begin{array}{c}0.0156 \\
(0.0165)\end{array}$ \\
\hline Vol-of-Vol & & & & & & & & & & & & & & & $\begin{array}{c}-0.0074 \\
(0.0309)\end{array}$ & $\begin{array}{c}0.0207 \\
(0.0244)\end{array}$ & $\begin{array}{c}-0.0206 \\
(0.0244)\end{array}$ \\
\hline
\end{tabular}


Table 8: Portfolio sorts and additional control variables

This table presents firm characteristics of portfolios sorted by the memory of volatility. The memory parameter is estimated with the GPH estimator and a bandwidth parameter of $m=N^{0.5}$. For the 1950-2015 period, we sort stocks for each month and form and hold the portfolio for one month. We report the average long memory parameter, memory parameters, market capitalization (Size), book-to-market values, prior returns (Momentum), illiquidity and jump statistics (BNS), Beta, Cokurtosis (CKT), Coskewness (CSK), idiosyncratic volatility (IVOL), kurtosis (KURT), skewness (SKEW), demand for lottery (MAX), and volatility of volatility (Vol-of-Vol) of quintile portfolios. The Q5-Q1 column reports the averages for the long memory minus short memory portfolio (LMS) with the according t-statistics in square brackets.

\begin{tabular}{lrrrrr|rr}
\hline & \multicolumn{1}{c}{ Q1 } & \multicolumn{1}{c}{ Q2 } & \multicolumn{1}{c}{ Q3 } & \multicolumn{1}{c}{ Q4 } & \multicolumn{1}{c}{ Q5 } & Q5-Q1 (LMS) & \\
\hline Memory & 0.0044 & 0.1295 & 0.2118 & 0.2975 & 0.4471 & 0.4427 & {$[202.7567]$} \\
Size & 11.6610 & 11.8630 & 12.0161 & 12.1707 & 12.3560 & 0.6950 & {$[23.3435]$} \\
Book-to-Market & 0.8934 & 0.9168 & 0.8993 & 0.8758 & 0.8996 & 0.0062 & {$[0.5910]$} \\
Momentum & 0.1681 & 0.1558 & 0.1522 & 0.1483 & 0.1284 & -0.0397 & {$[-14.2697]$} \\
Illiquidity & 0.0044 & 0.0040 & 0.0038 & 0.0040 & 0.0055 & 0.0010 & {$[3.9205]$} \\
BNS & -0.1994 & -0.0620 & -0.0255 & -0.0110 & 0.0036 & 0.2030 & {$[12.5035]$} \\
Beta & 0.8044 & 0.8458 & 0.8668 & 0.8874 & 0.8998 & 0.0954 & {$[13.5244]$} \\
REV & 0.0151 & 0.0128 & 0.0124 & 0.0118 & 0.0108 & -0.0043 & {$[-6.2043]$} \\
CKT & 0.7717 & 0.8385 & 0.8870 & 0.9271 & 0.9574 & 0.1857 & {$[15.0266]$} \\
CSK & -0.0462 & -0.0464 & -0.0455 & -0.0432 & -0.0410 & 0.0052 & {$[1.9815]$} \\
IVOL & 0.0245 & 0.0233 & 0.0226 & 0.0224 & 0.0233 & -0.0012 & {$[-3.5765]$} \\
KURT & 3.9543 & 3.8076 & 3.7205 & 3.6439 & 3.5518 & -0.4024 & {$[-40.4010]$} \\
SKEW & 0.2678 & 0.2461 & 0.2337 & 0.2232 & 0.2074 & -0.0604 & {$[-16.6647]$} \\
Max & 0.0672 & 0.0625 & 0.0602 & 0.0594 & 0.0609 & -0.0063 & {$[-7.1539]$} \\
Vol-of-Vol & 0.0616 & 0.0551 & 0.0527 & 0.0528 & 0.0577 & -0.0039 & {$[-4.4344]$} \\
\hline \hline
\end{tabular}


Table 9: Exposure to market long memory, aggregate volatility, and variance level

This table reports results from ? regressions for the 1950-2015 period. For each month, we regress excess stock returns on lagged firm characteristics including, memory parameters, market capitalization (Size), book-to-market values, prior returns (Momentum), illiquidity and jump statistics (BNS). We further control for Beta, Cokurtosis (CKT), Coskewness (CSK), idiosyncratic volatility (IVOL), kurtosis (KURT), skewness (SKEW), demand for lottery (MAX) and volatility of volatility (Vol-of-Vol), and exposure to market memory and aggregate volatility. Lastly, we control for the monthly level of variance (Variance level) in the last row. We report? standard errors using lags equal to the return horizon in parentheses. Stars indicate significance: ${ }^{*}$ significant at $p<0.10 ;{ }^{* *} p<0.05 ;{ }^{* * *} p<0.01$.

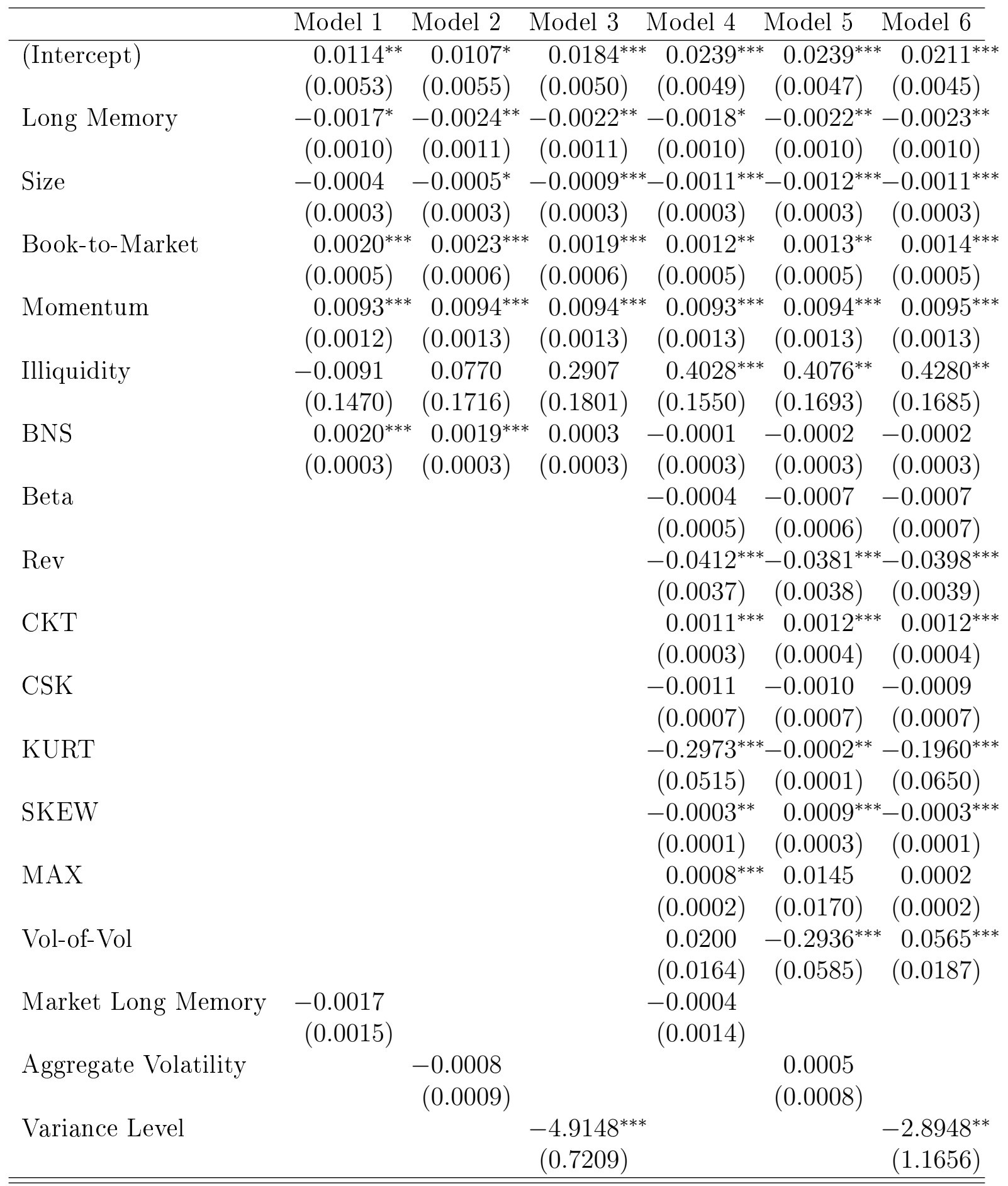


The Memory of Stock Return Volatility:

Asset Pricing Implications

Online Appendix 
Figure 2: Scatter plot of size and memory

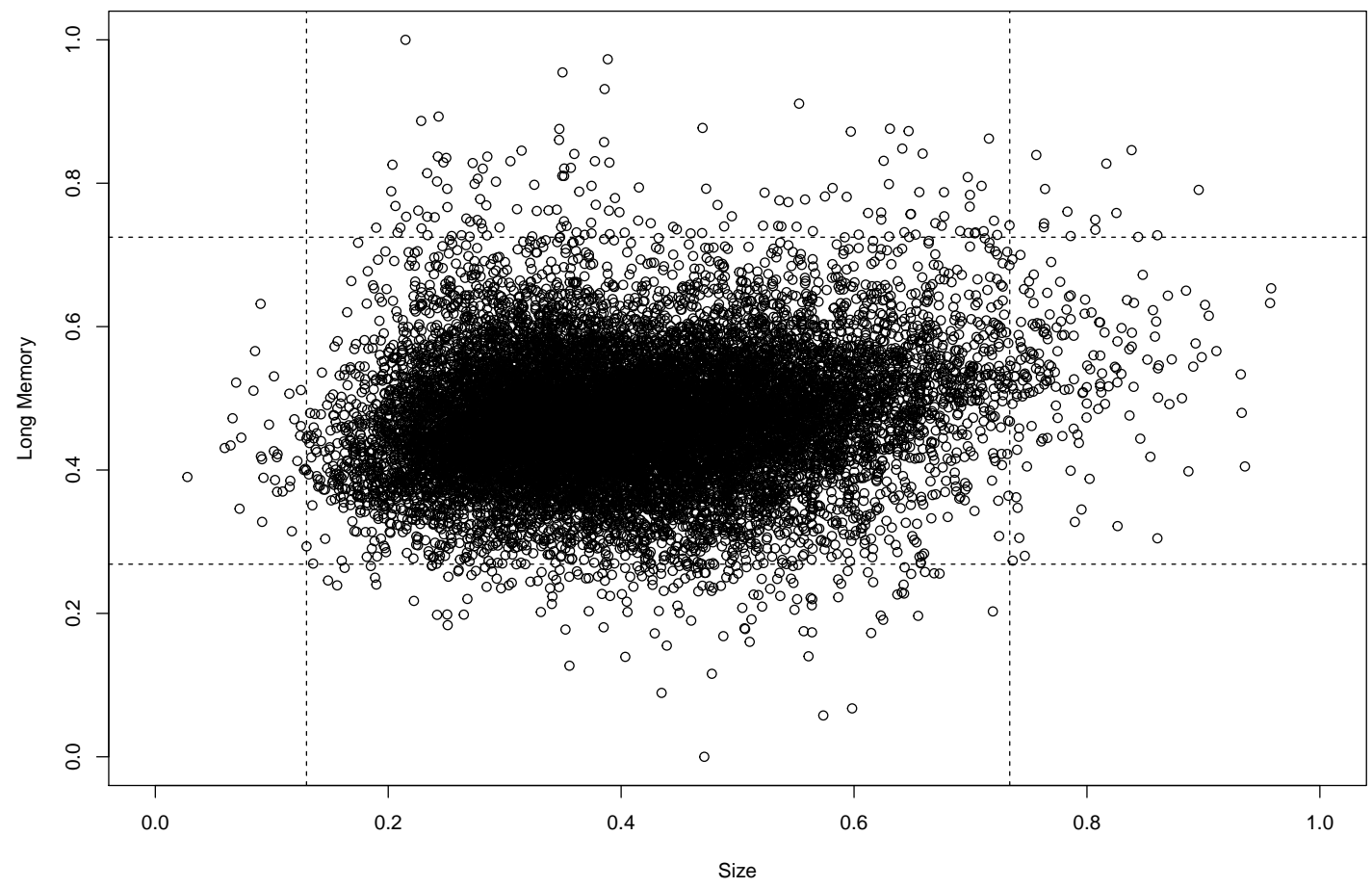

This figure plots the time series averages of size of U.S. stocks against their time series average of long memory estimated by the GPH estimator. Both size and memory are scaled to the interval between 0 and 1 . The dotted lines represent the 1 st and 99th quantile for size and long memory, respectively. 
Table 10: Sorted portfolio returns: residual long memory

This table reports average returns and risk-adjusted returns of equally weighted quintile portfolios. Each month, stocks are sorted by their residual long memory and we track the portfolio returns over the subsequent month. The memory parameter is estimated with the GPH estimator and a bandwidth parameter of $m=N^{0.5}$. Residual memory is calculated by regressing the memory parameter on size, book-to-market, momentum, and illiquidity (Model 1). Model 2 additionally includes the BNS jump test statistic. The one-month-ahead portfolio returns are regressed on risk factors in the Capital Asset Pricing Model (CAPM) and the ? five-factor model (FF5). The corresponding alphas are reported. We report ? standard errors using lags equal to the return horizon in parentheses. Stars indicate significance: ${ }^{*}$ significant at $p<0.10 ;{ }^{* *} p<0.05 ;{ }^{* * *} p<0.01$.

\begin{tabular}{lcccccc}
\hline \multicolumn{1}{c}{ Q1 } & Q2 & Q3 & Q4 & Q5 & Q5-Q1 (LMS) \\
\hline Panel A: Model 1 & \multicolumn{7}{c}{} \\
\hline CAPM & $0.0261^{* * *}$ & $0.0227^{* *}$ & $0.0286^{* * *}$ & $0.0188^{*}$ & 0.0146 & $-0.0115^{*}$ \\
& $(0.0101)$ & $(0.0100)$ & $(0.0098)$ & $(0.0101)$ & $(0.0097)$ & $(0.0060)$ \\
FF5 & 0.0049 & -0.0007 & 0.0034 & $-0.0090^{*}$ & $-0.0100^{*}$ & $-0.0149^{* *}$ \\
& $(0.0047)$ & $(0.0044)$ & $(0.0041)$ & $(0.0048)$ & $(0.0058)$ & $(0.0069)$ \\
\hline Panel B: Model 2 & & & & & \\
\hline CAPM & $0.0261^{* * *}$ & $0.0236^{* *}$ & $0.0293^{* * *}$ & $0.0176^{*}$ & 0.0141 & $-0.0120^{* *}$ \\
& $(0.0100)$ & $(0.0100)$ & $(0.0099)$ & $(0.0100)$ & $(0.0097)$ & $(0.0060)$ \\
FF5 & 0.0050 & 0.0006 & 0.0042 & $-0.0102^{* *}$ & $-0.0099^{*}$ & $-0.0149^{* *}$ \\
& $(0.0047)$ & $(0.0043)$ & $(0.0041)$ & $(0.0048)$ & $(0.0058)$ & $(0.0068)$ \\
\hline \hline
\end{tabular}


Table 11: Sorted portfolio returns: predictability

This table reports average returns and risk-adjusted returns of equally weighted quintile portfolios. Each month, stocks are sorted by their predictability of volatility and we track the portfolio returns over the subsequent month. The predictability is measured by the adjusted $R^{2}$ using the most recent five years of monthly volatility in the HAR(1) model. The one-month-ahead portfolio returns are regressed on risk factors in the Capital Asset Pricing Model (CAPM) and the ? five-factor model (FF5). The corresponding alphas are reported. We report ? standard errors using lags equal to the return horizon in parentheses. Stars indicate significance: ${ }^{*}$ significant at $p<0.10 ;{ }^{* *} p<0.05 ;{ }^{* * *} p<0.01$.

\begin{tabular}{lcccccc}
\hline & Q1 & Q2 & Q3 & Q4 & Q5 & Q5-Q1 (LMS) \\
\hline Mean return & $0.1434^{* * *}$ & $0.1390^{* * *}$ & $0.1313^{* * *}$ & $0.1303^{* * *}$ & $0.1244^{* * *}$ & $-0.0190^{*}$ \\
& $(0.0343)$ & $(0.0341)$ & $(0.0334)$ & $(0.0337)$ & $(0.0364)$ & $(0.0109)$ \\
FF5 & $0.0405^{* * *}$ & $0.0244^{* * *}$ & $0.0191^{* *}$ & 0.0112 & 0.0018 & $-0.0387^{* * *}$ \\
& $(0.0119)$ & $(0.0089)$ & $(0.0084)$ & $(0.0076)$ & $(0.0104)$ & $(0.0105)$ \\
\hline \hline
\end{tabular}


Table 12: Fama-MacBeth regressions - predictability

This table reports results from? regressions for the 1950-2015 period. Each month, excess stock returns are regressed on lagged firm characteristics including the predictability of volatility, market capitalization (Size), book-to-market values, prior returns (Momentum), illiquidity, and jump statistics (BNS). The predictability is measured by the adjusted $R^{2}$ using the most recent five years of monthly volatility in the HAR(1) model. We report ? standard errors using lags equal to the return horizon in parentheses. Stars indicate significance: ${ }^{*}$ significant at $p<0.10 ;{ }^{* *} p<0.05 ;{ }^{* * *} p<0.01$.

\begin{tabular}{|c|c|c|c|c|c|c|c|}
\hline & Model 1 & Model 2 & Model 3 & Model 4 & Model 5 & Model 6 & Model 7 \\
\hline \multirow[t]{2}{*}{ Intercept } & $0.0090^{* *}$ & * $0.0144^{* * *}$ & $* 0.0072^{* *}$ & $* 0.0077^{* *}$ & ${ }^{*} 0.0082^{* *}$ & $* 0.0086^{* *}$ & ** $0.0102^{*}$ \\
\hline & $(0.0025)$ & $(0.0048)$ & $(0.0025)$ & $(0.0024)$ & $(0.0025)$ & $(0.0025)$ & $(0.0056)$ \\
\hline \multirow[t]{2}{*}{ Predictability } & $-0.0055^{* *}$ & -0.0023 & $-0.0054^{* *}$ & $-0.0058^{* *}$ & $*-0.0059^{* *}$ & $*-0.0051^{* *}$ & ${ }^{k}-0.0023$ \\
\hline & $(0.0022)$ & $(0.0018)$ & $(0.0022)$ & $(0.0021)$ & $(0.0022)$ & $(0.0022)$ & $(0.0017)$ \\
\hline \multirow[t]{2}{*}{ Size } & & $-0.0006^{* *}$ & & & & & -0.0005 \\
\hline & & $(0.0003)$ & & & & & $(0.0003)$ \\
\hline \multirow[t]{2}{*}{ Book-to-Market } & & & $0.0022^{* *}$ & & & & $0.0025^{* * *}$ \\
\hline & & & $(0.0005)$ & & & & $(0.0006)$ \\
\hline \multirow[t]{2}{*}{ Momentum } & & & & $0.0053^{* *}$ & & & $0.0092^{* * *}$ \\
\hline & & & & $(0.0015)$ & & & $(0.0013)$ \\
\hline \multirow[t]{2}{*}{ Illiquidity } & & & & & $0.1738^{* *}$ & & 0.1192 \\
\hline & & & & & $(0.0873)$ & & $(0.1668)$ \\
\hline \multirow[t]{2}{*}{ BNS } & & & & & & $0.0024^{* *}$ & $0.0020^{* * *}$ \\
\hline & & & & & & $(0.0004)$ & $(0.0003)$ \\
\hline
\end{tabular}


Table 13: Long memory and industries

This table reports descriptive statistics for the memory parameter of industry portfolios. for the 1926-2015 period. The memory parameter is estimated with the GPH estimator and a bandwidth parameter of $m=N^{0.5}$. SD stands for the standard deviation. Min and Max stand for the minimum and maximum observation over the sample period.

\begin{tabular}{|c|c|c|c|c|c|c|}
\hline & Non-Durables & Durables & Manufacturing & Energy & Chemicals & Business Equipment \\
\hline Mean & 0.21 & 0.22 & 0.22 & 0.21 & 0.24 & 0.19 \\
\hline Median & 0.21 & 0.22 & 0.21 & 0.21 & 0.23 & 0.20 \\
\hline $\mathrm{SD}$ & 0.06 & 0.05 & 0.06 & 0.08 & 0.10 & 0.08 \\
\hline Min & 0.02 & -0.02 & 0.11 & -0.03 & -0.04 & -0.11 \\
\hline Max & 0.37 & 0.39 & 0.44 & 0.55 & 0.80 & 0.56 \\
\hline Skewness & 0.32 & -0.06 & 1.64 & 0.34 & 1.08 & -0.29 \\
\hline \multirow[t]{2}{*}{ Kurtosis } & 3.48 & 4.22 & 6.33 & 4.00 & 6.13 & 4.22 \\
\hline & Telecommunication & Utilities & Shops & Healthcare & Money Finance & Other \\
\hline Mean & 0.20 & 0.21 & 0.23 & 0.23 & 0.21 & 0.21 \\
\hline Median & 0.21 & 0.21 & 0.22 & 0.22 & 0.20 & 0.21 \\
\hline SD & 0.09 & 0.08 & 0.05 & 0.08 & 0.07 & 0.07 \\
\hline Min & -0.30 & -0.15 & 0.10 & -0.01 & -0.02 & -0.05 \\
\hline Max & 0.47 & 0.53 & 0.39 & 0.58 & 0.45 & 0.43 \\
\hline Skewness & -0.78 & -0.29 & 0.82 & 1.08 & 0.03 & -0.47 \\
\hline Kurtosis & 5.77 & 5.39 & 3.53 & 5.39 & 3.92 & 5.10 \\
\hline
\end{tabular}


Table 14: Long memory and Fama-French portfolios

This table reports the memory parameter for decile portfolios sorted Size, Book-to-Market and Momentum for the 1950-2015 period. The last column reports the average of the HighMinus-Low $(D 10-D 1)$ portfolio. The memory parameter is estimated with the GPH estimator and a bandwidth parameter of $m=N^{0.5}$.

\begin{tabular}{lcccccccccrr}
\hline & D1 & D2 & D3 & D4 & D5 & D6 & D7 & D8 & D9 & D10 & D10-D1 \\
\hline \hline Size & 0.3425 & 0.5483 & 0.5162 & 0.4799 & 0.4955 & 0.4489 & 0.4349 & 0.4397 & 0.4159 & 0.3860 & 0.0436 \\
Book-to-Market & 0.3382 & 0.4249 & 0.4334 & 0.4544 & 0.4808 & 0.5062 & 0.5090 & 0.5326 & 0.4905 & 0.6149 & 0.2767 \\
Momentum & 0.6184 & 0.6202 & 0.6138 & 0.5527 & 0.5215 & 0.4896 & 0.4237 & 0.3635 & 0.3034 & 0.1952 & -0.4232 \\
\hline \hline
\end{tabular}


Table 15: Sorted portfolio returns: alternative GPH estimators

This table reports average returns and risk-adjusted returns of equally weighted quintile portfolios for the 1926-2015 period. For each month, stocks are sorted by their memory parameter estimate and we track the portfolio returns over the subsequent month. The memory parameter is estimated with the GPH estimator and a bandwidth parameter of $m=N^{0.6}, m=N^{0.7}$ or $m=N^{0.8}$ in Panels A-C. The GPH estimator is applied to absolute returns and $m=N^{0.5}$ in Panel D. The one-month-ahead portfolio returns are regressed on risk factors in the ? five-factor model (FF5). The average return and the corresponding alphas are reported. We report ? standard errors using lags equal to the return horizon in parentheses. Stars indicate significance: ${ }^{*}$ significant at $p<0.10 ;{ }^{* *} p<0.05 ;{ }^{* * *} p<0.01$.

\begin{tabular}{|c|c|c|c|c|c|c|}
\hline & Q1 & Q2 & Q3 & Q4 & Q5 & Q5-Q1 (L1 \\
\hline \multicolumn{7}{|c|}{ Panel A: GPH $m=N^{0.6}$} \\
\hline \multirow[t]{2}{*}{ Mean return } & $0.1347^{* *}$ & ${ }^{*} 0.1353^{* *}$ & $1316^{* * *}$ & $0.1248^{* * *}$ & * $0.1167^{* *}$ & ${ }^{*}-0.0180^{* *}$ \\
\hline & $(0.0345)$ & $(0.0347)$ & $(0.0338)$ & $(0.0345)$ & $(0.0331)$ & $(0.0089)$ \\
\hline \multirow[t]{2}{*}{ FF5 } & $0.0219^{* *}$ & $0.0174^{*}$ & 0.0081 & 0.0052 & -0.0009 & $-0.0228^{* *}$ \\
\hline & $(0.0106)$ & $(0.0090)$ & $(0.0074)$ & $(0.0076)$ & $(0.0094)$ & $(0.0095)$ \\
\hline \multicolumn{7}{|c|}{ Panel B: GPH $m=N^{0.7}$} \\
\hline \multirow[t]{2}{*}{ Mean return } & $0.1426^{* * *}$ & ${ }^{*} 0.1313^{* *}$ & 0.1200 & 0.12 .00 & * $0.1155^{* *}$ & $\overline{-0}$ \\
\hline & $(0.0357)$ & $(0.0345)$ & $(0.0343)$ & $(0.0331)$ & $(0.0330)$ & $(0$. \\
\hline \multirow{2}{*}{ FF5 } & $0.0291^{* * *}$ & * 0.0131 & 0.0074 & 0.0070 & -0.0043 & $-0.0334^{* * *}$ \\
\hline & $(0.0105)$ & $(0.0093)$ & $(0.0078)$ & $(0.0076)$ & $(0.0088)$ & \\
\hline \multicolumn{7}{|c|}{ Panel C: GPH $m=N^{0.8}$} \\
\hline \multirow[t]{2}{*}{ Mean return } & $0.1415^{* * *}$ & 0.137 & ${ }^{*} 0.1248^{* *}$ & $0.1208^{* * *}$ & 0.118 & $-0.0232^{* *}$ \\
\hline & $(0.0361)$ & $(0.036$ & $(0.0335)$ & $(0.0335)$ & $(0.031$ & $(0$. \\
\hline \multirow[t]{2}{*}{ FF5 } & $0.0293^{* * *}$ & * $0.0170^{* *}$ & 0.0090 & -0.0010 & -0.0022 & $-0.0314^{* * *}$ \\
\hline & $(0.0103)$ & $(0.0082)$ & $(0.0086)$ & $(0.0085)$ & $(0.0084)$ & $(0.0$ \\
\hline \multicolumn{7}{|c|}{ Panel D: GPH Absolute Returns $m=N^{0.5}$} \\
\hline \multirow[t]{2}{*}{ Mean return } & $0.1417^{* *}$ & ${ }^{*} 0.1321^{* *}$ & ${ }^{*} 0.1306^{* * *}$ & $0.1264^{* *}$ & $0.1123^{* *}$ & $-0.0294^{* * *}$ \\
\hline & $(0.0335)$ & $(0.0331)$ & $(0.0341)$ & $(0.0342)$ & $(0.0360)$ & \\
\hline \multirow[t]{2}{*}{ FF5 } & $0.0202^{* *}$ & 0.0145 & 0.0106 & 0.0074 & -0.0026 & $-0.0228^{* *}$ \\
\hline & $(0.0102)$ & $(0.0091)$ & $(0.0074)$ & $(0.0074)$ & $(0.0105)$ & $(0.0105)$ \\
\hline
\end{tabular}


Table 16: Sorted portfolio returns: alternative LW estimators

This table reports average returns and risk-adjusted returns of equally weighted quintile portfolios for the 1926-2015 period. For each month, stocks are sorted by their memory parameter estimate and we track the portfolio returns over the subsequent month. The memory parameter is estimated with the LW estimator and a bandwidth parameter of $m=N^{0.5}, m=N^{0.6}, m=N^{0.7}$ or $m=N^{0.8}$ in Panels A-D. The LW estimator is applied to absolute returns and $m=N^{0.5}$ in Panel E. The one-month-ahead portfolio returns are regressed on risk factors in the ? five-factor model (FF5). The average return and the corresponding alphas are reported. We report ? standard errors using lags equal to the return horizon in parentheses. Stars indicate significance: ${ }^{*}$ significant at $p<0.10$; ${ }^{* *} p<0.05 ;{ }^{* * *} p<0.01$.

\begin{tabular}{|c|c|c|c|c|c|c|}
\hline & Q1 & $\overline{\mathrm{Q} 2}$ & Q3 & $\overline{\mathrm{Q} 4}$ & Q5 & Q5-Q1 (LMS) \\
\hline \multicolumn{7}{|c|}{ Panel A: LW $m=N^{0.5}$} \\
\hline \multirow[t]{2}{*}{ Mean return } & $0.1391^{* *}$ & 29 & 130 & $0.1256^{* * *}$ & $0.1181^{* * *}$ & -0. \\
\hline & $(0.0333)$ & $(0.0332)$ & $(0.0333)$ & $(0.0351)$ & $(0.0358)$ & $(0.0100)$ \\
\hline \multirow[t]{2}{*}{ FF5 } & $0.0309^{* *}$ & *0.0133 & 0.0092 & 0.0009 & -0.0012 & $-0.0321^{* * *}$ \\
\hline & $(0.0115)$ & $(0.0086)$ & $(0.0077)$ & $(0.0076)$ & $(0.0097)$ & $(0.0109)$ \\
\hline \multicolumn{7}{|c|}{ Panel B: LW $m=N^{0.6}$} \\
\hline \multirow{2}{*}{ Mean return } & $0.1363^{* *}$ & 0 & 0.1008 & 0.1221 & $0.1182^{* * *}$ & -0 \\
\hline & $(0.0342)$ & $(0,0344)$ & $(0.0341)$ & $(0.0345)$ & $(0.0334)$ & 9) \\
\hline \multirow[t]{2}{*}{ FF5 } & $0.0254^{* *}$ & $0.0176^{* *}$ & 0.0079 & 0.0017 & 0.0000 & $-0.0254^{* *}$ \\
\hline & $(0.0110)$ & $(0.0088)$ & $(0.0079)$ & $(0.0075)$ & $(0.0094)$ & $(0.0103)$ \\
\hline \multicolumn{7}{|c|}{ Panel C: LW $m=N^{0.7}$} \\
\hline \multirow[t]{2}{*}{ Mean return } & $0.1435^{* *}$ & .1324 & $0.1307^{* * *}$ & ${ }^{*} 0.1238^{* *}$ & 0.11 & $-0.0298^{*}$ \\
\hline & $(0.035$ & $0.0349)$ & $(0.0338)$ & $(0.0343)$ & $(0.03$ & 1) \\
\hline \multirow[t]{2}{*}{ FF5 } & $0.0324^{* *}$ & *0.0131 & 0.0093 & 0.0054 & -0.0069 & $-0.0393^{* * *}$ \\
\hline & $(0.0106)$ & $(0.0092)$ & $(0.0081)$ & $(0.0079)$ & $(0.0090)$ & $(0.0105)$ \\
\hline \multicolumn{7}{|c|}{ Panel D: LW $m=N^{0.8}$} \\
\hline \multirow[t]{2}{*}{ Mean return } & $0.1427^{* *}$ & $0.1370^{* *}$ & $0.1275^{* * *}$ & * $0.1230^{* * *}$ & $0.1135^{* * *}$ & $-0.0292^{* * *}$ \\
\hline & $(0.0366)$ & $(0.0351)$ & $(0.0344)$ & $(0.0334)$ & $(0.0315)$ & $(0.0112)$ \\
\hline \multirow[t]{2}{*}{ FF5 } & $0.0298^{* *}$ & *0.0191** & 0.0080 & 0.0014 & -0.0053 & $-0.0351^{* * *}$ \\
\hline & $(0.0108)$ & $(0.0088)$ & $(0.0082)$ & $(0.0078)$ & $(0.0093)$ & $(0.0106)$ \\
\hline \multicolumn{7}{|c|}{ Panel E: LW Absolute Returns $m=N^{0.5}$} \\
\hline \multirow[t]{2}{*}{ Mean return } & $0.1445^{* *}$ & * $0.1327^{* *}$ & * $0.1336^{* * *}$ & ${ }^{*} 0.1175^{* *}$ & $0.1141^{* *}$ & ${ }^{*}-0.0303^{* *}$ \\
\hline & $(0.033$ & $(0.0324)$ & $(0.0344)$ & $(0.0337)$ & $(0.0369)$ & $(0.0121)$ \\
\hline \multirow[t]{2}{*}{ FF5 } & $0.0264^{* *}$ & 0.0147 & 0.0099 & 0.0021 & -0.0029 & $-0.0293^{* * *}$ \\
\hline & $(0.0103)$ & $(0.0091)$ & $(0.0075)$ & $(0.0076)$ & $(0.0108)$ & $(0.0112)$ \\
\hline
\end{tabular}


Table 17: Cross-sectional regressions: alternative estimators

This table reports results from ? regressions for the 1950-2015 period. for each month, excess stock returns are regressed on the lagged memory parameters in Panel A. Panel B further includes additional lagged firm characteristics, which are market capitalization (Size), book-to-market values, prior returns (Momentum), illiquidity, and jump statistics (BNS). The memory parameter is estimated by applying the GPH or the LW estimator and a bandwidth parameter of $m=N^{0.5}, m=N^{0.6}, m=N^{0.7}$ or $m=N^{0.8}$ to squared or absolute returns. We report ? standard errors using lags equal to the return horizon in parentheses. Stars indicate the significance: ${ }^{*}$ significant at $p<0.10 ;{ }^{* *} p<0.05$; ${ }^{* * *} p<0.01$.

\begin{tabular}{|c|c|c|c|c|c|c|c|c|c|}
\hline & \multicolumn{3}{|c|}{ GPH } & \multicolumn{4}{|c|}{ LW } & \multirow[b]{2}{*}{$N^{0.8}$} & \multirow[b]{2}{*}{ Abs. $N^{0.5}$} \\
\hline & $N^{0.6}$ & $N^{0.7}$ & $N^{0.8}$ & Abs. $N^{0.5}$ & $N^{0.5}$ & $N^{0.6}$ & $N^{0.7}$ & & \\
\hline \multicolumn{10}{|c|}{ Panel A: Simple Regressions } \\
\hline \multirow[t]{2}{*}{ Intercept } & $0.0089^{* * *}$ & ${ }^{*} 0.0091^{* * *}$ & ${ }^{*} 0.0091^{* * *}$ & 0.0001 & 0.0032 & 0.0031 & 0.0084 & 0.0030 & 0.0001 \\
\hline & $(0.0026)$ & $(0.0026)$ & $(0.00$ & $(0.0$ & $(0.0026)$ & $(0.0026)$ & $(0.0027)$ & $(0.00$ & $(0.00$ \\
\hline \multirow[t]{2}{*}{ Long Memory } & $-0.0039^{*}$ & $-0.0062^{* *}$ & $-0.0075^{* *}$ & $-0.0045^{* *}$ & $-0.0047^{* *}$ & $-0.0053^{*}$ & $-0.0084^{* *}$ & $-0.0104^{* *}$ & $-0.0060^{* *}$ \\
\hline & $(0.0022)$ & $(0.0028)$ & $(0.0036)$ & $(0.0019)$ & $(0.0022)$ & $(0.0029)$ & $(0.0038)$ & $(0.0049)$ & $(0.0025)$ \\
\hline \multicolumn{10}{|c|}{ Panel B: Multiple Regressions } \\
\hline \multirow[t]{2}{*}{ Intercept } & $0.0106^{*}$ & $0.0109^{*}$ & $0.0110^{*}$ & $0.0111^{* *}$ & $0.0106^{*}$ & $0.0106^{*}$ & $0.0109^{*}$ & $0.0111^{*}$ & $0.0110^{*}$ \\
\hline & $(0.0056)$ & $(0.0056)$ & $(0.0057)$ & $(0.0056)$ & $(0.0056)$ & $(0.0056)$ & $(0.0056)$ & $(0.0057)$ & $(0.0056)$ \\
\hline \multirow[t]{2}{*}{ Long Memory } & $-0.0026^{*}$ & $-0.0044^{* *}$ & $-0.0047^{*}$ & $-0.0027^{* *}$ & $-0.0030^{* *}$ & $-0.0033^{*}$ & $-0.0063^{* *}$ & $-0.0071^{*}$ & $-0.0036^{* *}$ \\
\hline & $(0.0015)$ & $(0.0021)$ & $(0.0028)$ & $(0.0013)$ & $(0.0015)$ & $(0.0019)$ & $(0.0028)$ & $(0.0039)$ & $(0.0017)$ \\
\hline \multirow[t]{2}{*}{ Size } & -0.0005 & $-0.0005^{*}$ & $-0.0005^{*}$ & $-0.0005^{*}$ & -0.0005 & -0.0005 & -0.0005 & -0.0005 & -0.0005 \\
\hline & $(0.0003)$ & $(0.0003)$ & $(0.0003)$ & $(0.0003)$ & $(0.0003)$ & $(0.0003)$ & $(0.0003)$ & $(0.0003)$ & $(0.0003)$ \\
\hline \multirow[t]{2}{*}{ Book-to-Market } & $0.0024^{* * *}$ & $* 0.0024^{* * *}$ & $* 0.0023^{* * *}$ & $0.0024^{* * *}$ & $* 0.0024^{* * *}$ & * $0.0024^{* * *}$ & $0.0024^{* * *}$ & $0.0023^{* * *}$ & $0.0024^{* * *}$ \\
\hline & $(0.0006)$ & $(0.0006)$ & $(0.0006)$ & $(0.0006)$ & $(0.0006)$ & $(0.0006)$ & $(0.0006)$ & $(0.0006)$ & $(0.0006)$ \\
\hline \multirow[t]{2}{*}{ Momentum } & $0.0094^{* * *}$ & $* 0.0095^{* * *}$ & * $0.0094^{* * *}$ & $0.0095^{* * *}$ & $0.0095^{* * *}$ & $0.0095^{* * *}$ & * $0.0094^{* * *}$ & * $0.0094^{* * *}$ & $0.0095^{* * *}$ \\
\hline & $(0.0013)$ & $(0.0013)$ & $(0.0013)$ & $(0.0013)$ & $(0.0013)$ & $(0.0013)$ & $(0.0013)$ & $(0.0013)$ & $(0.0013)$ \\
\hline \multirow[t]{2}{*}{ Illiquidity } & 0.0987 & 0.0952 & 0.0926 & 0.0927 & 0.0993 & 0.0991 & 0.0971 & 0.0924 & 0.0933 \\
\hline & $(0.1764)$ & $(0.1754)$ & $(0.1752)$ & $(0.1759)$ & $(0.1763)$ & $(0.1765)$ & $(0.1753)$ & $(0.1742)$ & $(0.1752)$ \\
\hline \multirow[t]{2}{*}{ BNS } & $0.0020^{* * *}$ & * $0.0020^{* * *}$ & $* 0.0020^{* * * *}$ & $0.0020^{* * *}$ & $0.0020^{* * *}$ & $0.0020^{* * *}$ & * $0.0020^{* * *}$ & * $0.0020^{* * *}$ & $0.0020^{* * *}$ \\
\hline & $(0.0003)$ & $(0.0003)$ & $(0.0003)$ & $(0.0003)$ & $(0.0003)$ & $(0.0003)$ & $(0.0003)$ & $(0.0003)$ & $(0.0003)$ \\
\hline
\end{tabular}


Table 18: Sorted portfolio returns: alternative holding periods

This table reports average returns and risk-adjusted returns of equally weighted quintile portfolios for the 1926-2015 period. For each month, stocks are sorted by their memory parameter estimate and we track the portfolio returns over the subsequent one, two, three, four and five years in Panel A, B, C, D and E, respectively. The memory parameter is estimated with the GPH estimator and a bandwidth parameter of $m=N^{0.5}$. The onemonth-ahead portfolio returns are regressed on risk factors in the Capital Asset Pricing Model (CAPM) and the ? five-factor model (period starts in 1963) (FF5). The mean returns and the corresponding alphas are reported. We report ? standard errors using lags equal to the return horizon in parentheses. Stars indicate significance: ${ }^{*}$ significant at $p<0.10 ;{ }^{* *} p<0.05 ;{ }^{* * *} p<0.01$.

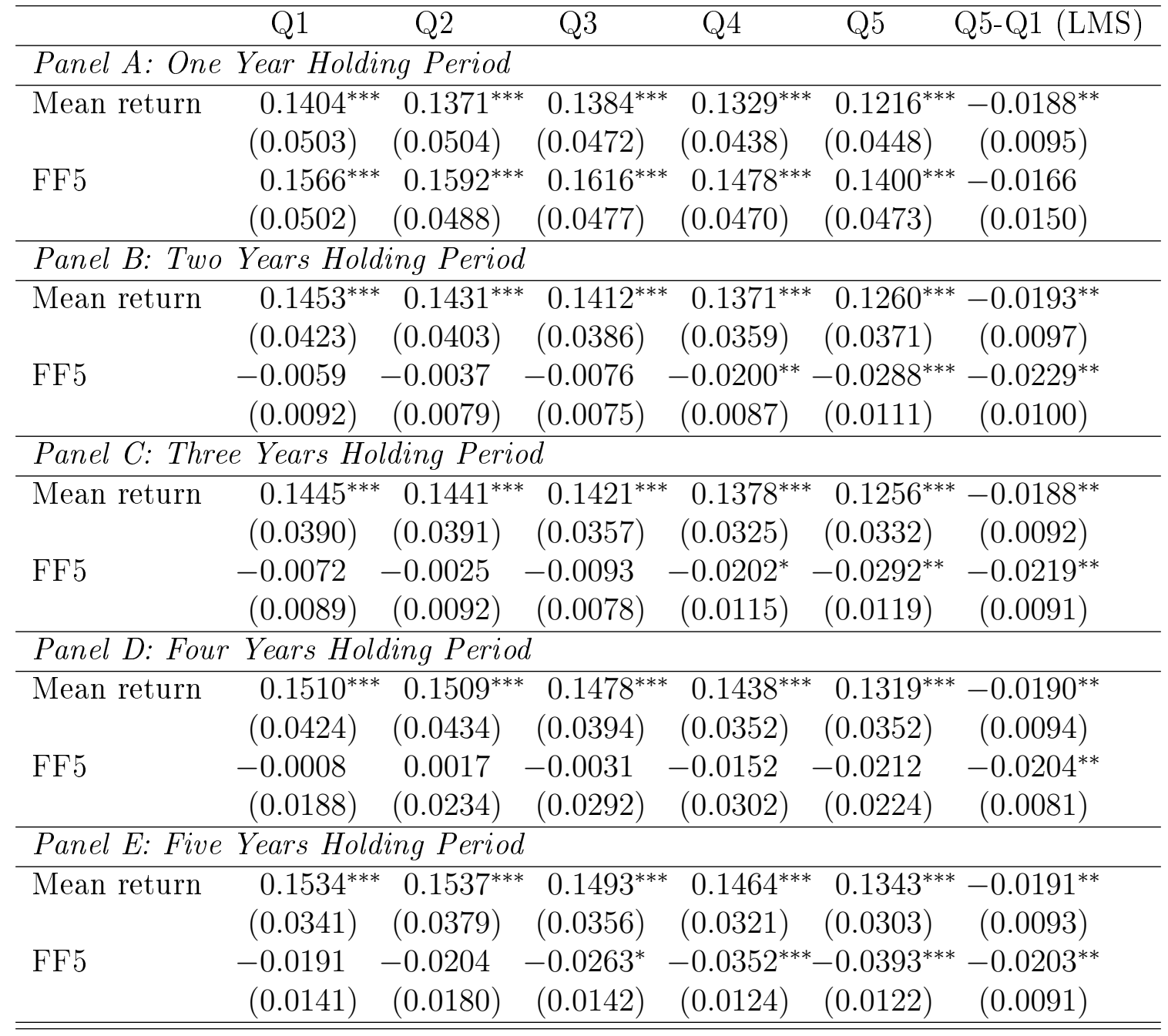


Table 19: Sorted portfolio returns: high frequency data

This table reports average returns and risk-adjusted returns of quintile portfolios for the 1996-2015 period. for each month, stocks are sorted by their long memory parameter estimate and we track the portfolio returns over the subsequent month. The one-monthahead portfolio returns are regressed on risk factors in the Capital Asset Pricing Model (CAPM), the ? 3-factor model (FF3), the ? 5-factor model (FF5), and the ? q-model (HXZ). The corresponding alphas are reported. We report ? standard errors using lags equal to the return horizon in parentheses. The memory parameter is estimated using a month of 5-min returns and the GPH estimator and a bandwidth parameter of $m=N^{0.5}$. Stars indicate significance: ${ }^{*}$ significant at $p<0.10 ;{ }^{* *} p<0.05 ;{ }^{* * *} p<0.01$.

\begin{tabular}{lcccccc}
\hline & $\mathrm{Q} 1$ & $\mathrm{Q} 2$ & $\mathrm{Q} 3$ & $\mathrm{Q} 4$ & $\mathrm{Q} 5$ & $\mathrm{Q} 5-\mathrm{Q} 1(\mathrm{LMS})$ \\
\hline Mean return & $0.1638^{* * *}$ & $0.1246^{* * *}$ & $0.1091^{* *}$ & $0.1025^{* *}$ & $0.0754^{*}$ & $-0.0883^{* * *}$ \\
& $(0.0441)$ & $(0.0474)$ & $(0.0461)$ & $(0.0438)$ & $(0.0445)$ & $(0.0176)$ \\
\hline CAPM & $0.1508^{* * *}$ & $0.1138^{* * *}$ & $0.0980^{* *}$ & $0.0881^{* *}$ & 0.0600 & $-0.0908^{* * *}$ \\
& $(0.0403)$ & $(0.0432)$ & $(0.0444)$ & $(0.0405)$ & $(0.0417)$ & $(0.0182)$ \\
FF3 & $0.1369^{* * *}$ & $0.1040^{* *}$ & $0.0798^{*}$ & $0.0768^{*}$ & 0.0633 & $-0.0736^{* * *}$ \\
FF5 & $(0.0429)$ & $(0.0437)$ & $(0.0457)$ & $(0.0433)$ & $(0.0434)$ & $(0.0193)$ \\
& 0.0963 & 0.0643 & 0.0395 & 0.0558 & 0.0367 & $-0.0597^{* *}$ \\
HXZ & $(0.0644)$ & $(0.0638)$ & $(0.0612)$ & $(0.0581)$ & $(0.0563)$ & $(0.0257)$ \\
& 0.0558 & 0.0194 & -0.0088 & 0.0259 & -0.0169 & $-0.0727^{* *}$ \\
\hline \hline
\end{tabular}


Table 20: Portfolio sorts and characteristics - liquidity effects

This table presents firm characteristics of portfolios sorted by the memory of volatility. The memory parameter is estimated with the GPH estimator and a bandwidth parameter of $m=N^{0.5}$. From 1950 to 015 , we sort stocks for each month and form and hold the portfolio for one month. We report the average long memory parameter, size, momentum, and illiquidity, BNS statistic and BNS indicator function of quintile portfolios. The Q5-Q1 column reports the averages for the long memory minus short memory portfolio (LMS) with the according t-statistics in square brackets. The complete sample filtered by illiquid stocks measured by missing observations (missing or zero return). Panel A reports our main results. Panel B (D) only considers the $50 \%$ of the stocks with the least zero (missing) returns over the lifetime of the stock. Panel C (E) requires a stock to have zero (missing) returns on less than $10 \%$ of the days over its lifetime to be included.

\begin{tabular}{|c|c|c|c|c|c|c|c|}
\hline \multirow{2}{*}{\multicolumn{8}{|c|}{$\begin{array}{ll}\text { Q1 } & \text { Q2 } \\
\text { Panel A: Complete Sample } & \end{array}$}} \\
\hline & & & & & & & \\
\hline Memory & 0.0044 & 0.1295 & 0.2118 & 0.2975 & 0.4471 & 0.4427 & {$[202.7567]$} \\
\hline Size & 11.6610 & 11.8630 & 12.0161 & 12.1707 & 12.3560 & 0.6950 & [23.3435] \\
\hline BNS & -0.1994 & -0.0620 & -0.0255 & -0.0110 & 0.0036 & 0.2030 & [12.5035] \\
\hline BNS-I & 0.0177 & 0.0126 & 0.0106 & 0.0087 & 0.0074 & -0.0103 & {$[-24.2588]$} \\
\hline \multicolumn{8}{|c|}{ Panel B: Median of Zero-Return-Proportion } \\
\hline Long Memory & 0.0099 & 0.1347 & 0.2156 & 0.2990 & 0.4442 & 0.4343 & {$[187.7904]$} \\
\hline Size & 12.1271 & 12.3084 & 12.4651 & 12.6202 & 12.8074 & 0.6804 & [26.9105] \\
\hline BNS & -0.2095 & -0.0817 & -0.0493 & -0.0377 & -0.0236 & 0.1859 & {$[11.3556]$} \\
\hline BNS-I & 0.0173 & 0.0123 & 0.0105 & 0.0088 & 0.0073 & -0.0100 & {$[-22.2307]$} \\
\hline \multicolumn{8}{|c|}{ Panel C: Zero-Return-Proportion $<10 \%$} \\
\hline Long Memory & 0.0354 & 0.1577 & 0.2374 & 0.3184 & 0.4540 & 0.4187 & {$[140.0909]$} \\
\hline Size & 13.4975 & 13.5595 & 13.6571 & 13.8167 & 14.0044 & 0.5069 & [17.6627] \\
\hline BNS & -0.2148 & -0.1017 & -0.0854 & -0.0775 & -0.0707 & 0.1441 & [6.8881] \\
\hline BNS-I & 0.0153 & 0.0113 & 0.0105 & 0.0085 & 0.0070 & -0.0083 & {$[-11.4569]$} \\
\hline \multicolumn{8}{|c|}{ Panel D: Median of Missing-Return-Proportion } \\
\hline Long Memory & 0.0188 & 0.1448 & 0.2281 & 0.3139 & 0.4615 & 0.4426 & {$[199.3277]$} \\
\hline Size & 12.3504 & 12.4568 & 12.5820 & 12.7180 & 12.8816 & 0.5313 & {$[16.5373]$} \\
\hline BNS & -0.1923 & -0.0596 & -0.0270 & -0.0133 & -0.0022 & 0.1901 & {$[10.2357]$} \\
\hline BNS-I & 0.0164 & 0.0112 & 0.0099 & 0.0083 & 0.0068 & -0.0095 & {$[-18.4332]$} \\
\hline \multicolumn{8}{|c|}{ Panel E: Missing-Return-Proportion $<10 \%$} \\
\hline Long Memory & 0.0044 & 0.1295 & 0.2118 & 0.2975 & 0.4471 & 0.4427 & {$[202.7553]$} \\
\hline Size & 11.6611 & 11.8631 & 12.0161 & 12.1706 & 12.3561 & 0.6950 & [23.3444] \\
\hline BNS & -0.1993 & -0.0620 & -0.0255 & -0.0110 & 0.0037 & 0.2030 & {$[12.5028]$} \\
\hline BNS-I & 0.0177 & 0.0126 & 0.0106 & 0.0087 & 0.0073 & -0.0103 & {$[-24.2713]$} \\
\hline
\end{tabular}


Table 21: Cross-sectional regression - liquidity effects

This table presents the results from cross-sectional regressions for the 1950-2015 period. For each month, we regress the memory parameter of the cross-section on size and BNS. The memory parameter is estimated with the GPH estimator and a bandwidth parameter of $m=N^{0.5}$. We report the average $\beta$ coefficients and the according standard errors in parentheses below. Stars indicate significance: ${ }^{*}$ significant at $p<0.10 ;{ }^{* *} p<0.05$; ${ }^{* * *} p<0.01$. Row 1 reports the results using the complete sample. Row 2 (4) only considers the $50 \%$ of the stocks with the least zero (missing) returns over the lifetime of the stock. Panel 3 (5) requires a stock to have zero (missing) returns on less than $10 \%$ of the days over its lifetime to be included.

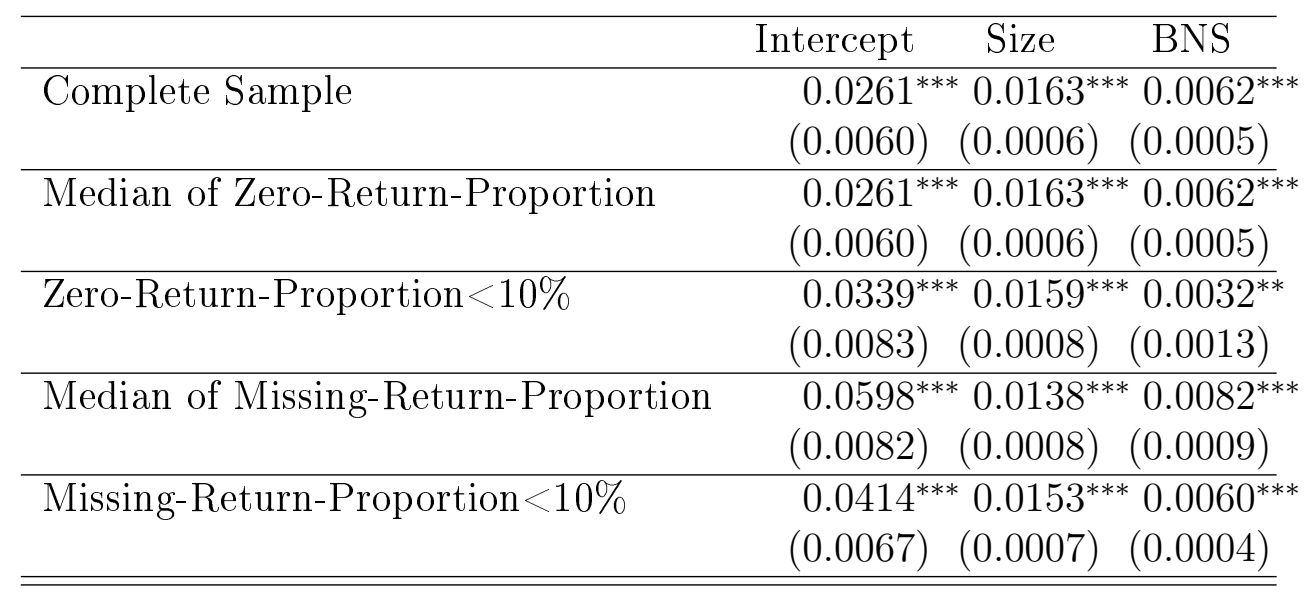

